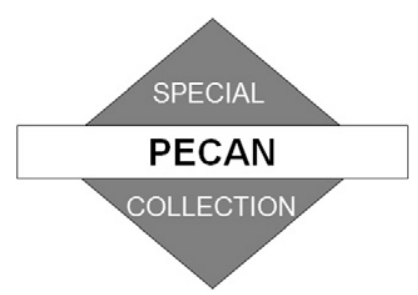

\title{
Estimating the Maximum Vertical Velocity at the Leading Edge of a Density Current
}

\author{
Dylan W. Reif, ${ }^{a}$ Howard B. Bluestein, ${ }^{a}$ TAMmy M. WeCKWerth, ${ }^{\mathrm{b}}$ ZACHARY B. WienhofF, ${ }^{\mathrm{a}}$ AND \\ MANDA B. CHASTEEN ${ }^{\mathrm{c}}$ \\ ${ }^{a}$ School of Meteorology, University of Oklahoma, Norman, Oklahoma; ${ }^{\mathrm{b}}$ Earth Observing Laboratory, National Center for \\ Atmospheric Research, Boulder, Colorado; ${ }^{\mathrm{c}}$ School of Meteorology, University of Oklahoma, and Cooperative Institute for \\ Mesoscale Meteorological Studies, and NOAA/OAR/National Severe Storms Laboratory, Norman, Oklahoma
}

(Manuscript received 30 January 2020, in final form 15 August 2020)

\begin{abstract}
The maximum upward vertical velocity at the leading edge of a density current is commonly $<10 \mathrm{~m} \mathrm{~s}^{-1}$. Studies of the vertical velocity, however, are relatively few, in part owing to the dearth of high-spatiotemporal-resolution observations. During the Plains Elevated Convection At Night (PECAN) field project, a mobile Doppler lidar measured a maximum vertical velocity of $13 \mathrm{~m} \mathrm{~s}^{-1}$ at the leading edge of a density current created by a mesoscale convective system during the night of 15 July 2015. Two other vertically pointing instruments recorded $8 \mathrm{~m} \mathrm{~s}^{-1}$ vertical velocities at the leading edge of the density current on the same night. This study describes the structure of the density current and attempts to estimate the maximum vertical velocity at their leading edges using the following properties: the density current depth, the slope of its head, and its perturbation potential temperature. The method is then be applied to estimate the maximum vertical velocity at the leading edge of density currents using idealized numerical simulations conducted in neutral and stable atmospheres with resting base states and in neutral and stable atmospheres with vertical wind shear. After testing this method on idealized simulations, this method is then used to estimate the vertical velocity at the leading edge of density currents documented in several previous studies. It was found that the maximum vertical velocity can be estimated to within $10 \%-15 \%$ of the observed or simulated maximum vertical velocity and indirectly accounts for parameters including environmental wind shear and static stability.
\end{abstract}

KEYWORDS: Density currents; Mesoscale processes; Lidars/Lidar observations; Radars/Radar observations; Mesoscale models

\section{Introduction}

An atmospheric density current is a common phenomenon often created by thunderstorm outflow. The cooler, denser air beneath the thunderstorm races outward at the surface, and the interface between the cooler, denser air and the environment is known as a gust front or outflow boundary (Fig. 1). This boundary can be seen on radar as a line of relatively enhanced radar reflectivity factor due to the convergence of scatterers such as insects, dirt, or seeds (e.g., Wilson and Schreiber 1986). The propagation speed of a density current has been a subject of many past studies (e.g., Benjamin 1968; Wakimoto 1982; Seitter 1986; Mahoney 1988; Smith and Reeder 1988; Grant and van den Heever 2016). The motion of the density current is governed by the horizontal pressure gradient force that arises from the horizontal gradient of density (high density within the density current to the lower density in the environment; e.g., Seitter 1986). Over the Great Plains, mesoscale convective systems (MCSs) are a common source of density currents, which are important to the maintenance of convective systems (Rotunno et al. 1988) and the initiation of new convection.

Corresponding author: Dylan W. Reif, dylanreif@ou.edu
Ascent associated with density currents contributes to the initiation and maintenance of convective systems (e.g., Rotunno et al. 1988; Crook and Moncrieff 1988; Shapiro 1992; Weisman and Rotunno 2004; Lane and Moncrieff 2015). Rotunno et al. (1988) described the "optimal state" for MCS maintenance by a density current as a balance between the baroclinically generated horizontal vorticity at the leading edge of a density current and the horizontal vorticity associated with the environmental shear. This balance results in a more vertically oriented updraft. Bryan and Rotunno (2014a) showed that in this optimal state, a density current with a $90^{\circ}$ slope has a vertical velocity that is effectively the system-relative (horizontal) wind speed. Weckwerth and Wakimoto (1992) showed how a combination of Kelvin-Helmholtz instability (KHI) and inertia gravity waves at the top of a density current can initiate convection. These features provide additional ascent acting in concert with the lift from the density current, resulting in focused areas of CI. Wilson and Megenhardt (1997) showed that parcels at the leading edge of the density current moving in the same direction as the wind direction of the steering level can result in air parcels remaining in that area for a longer period of time. This longer residence time at the leading edge of density currents resulted in more CI and more organized convection. 


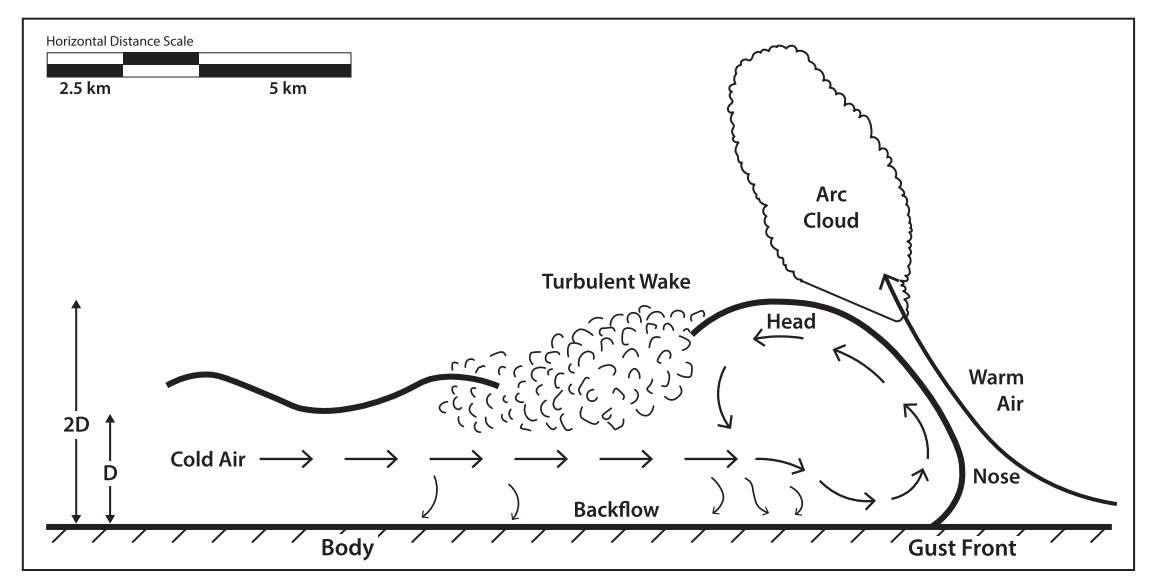

FIG. 1. Conceptual model of a density current. $D$ is the height of the cooler air far behind the head of the density current. Adapted from Droegemeier and Wilhelmson (1987).

However, while these density currents were sea breezes unassociated with a parent thunderstorm, it further illustrates the many factors that influence CI near density currents.

Despite the density currents' importance to CI, the vertical velocity at its leading edge has received less attention than its depth and propagation speed. Previous studies (both based on observations and numerical simulations) have shown that this maximum vertical velocity is commonly $<10 \mathrm{~m} \mathrm{~s}^{-1}$ (e.g., Charba 1974*; Mitchell and Hovermale 1977; Wakimoto 1982; Shapiro 1984*; Straka et al. 1993; Martner 1997; Geerts et al. 2006; Bryan and Rotunno 2014b; Soler et al. 2014*; see Table 1$).{ }^{1}$ The magnitude of the vertical velocity can be affected by several factors including the depth of the density current (e.g., Shapiro 1992), the system-relative wind speed (e.g., Wilson and Megenhardt 1997), and the environmental wind shear (e.g., Rotunno et al. 1988). However, there are other processes that may affect the vertical velocity, including Kelvin-Helmholtz billows and the circulation within the density current head. Kelvin-Helmholtz billows are typically generated near the top of the leading edge of the density current due to the release of KHI and move rearward with respect to the density current. Droegemeier and Wilhelmson (1987) showed that the circulation within the head of the density current alters its height and propagation speed. Along with ascent associated with that circulation, altering these two features could also affect the vertical velocity at the leading edge.

The shape of the density current is modified by the environmental stratification (e.g., Liu and Moncrieff 2000; White and Helfrich 2008; Seigel and van den Heever 2012) and the environmental shear (e.g., Xu 1992; Chen 1995; Bryan and Rotunno 2014b). In continuously stratified environments, as

\footnotetext{
${ }^{1}$ Those studies denoted with an asterisk $(*)$ indicate that the vertical velocities were recorded from instrumented towers, which are typically too short to record the true maximum vertical velocity, which may occur above them.
}

the stratification increases, the speed and depth of the density current decrease (Liu and Moncrieff 2000). In environments with strong vertical wind shear, the slope of the density current interface can become steep (sometimes becoming nearly vertically oriented). Hutson et al. (2019) attempted to find a relationship between the potential temperature perturbation of the density current and the slope of the density current head. They concluded that density currents with weaker potential temperature deficits will have steeper slope. Vertical wind shear and the depth of that shear layer also have an effect on altering the slope.

There have been numerous numerical simulations of density currents (e.g., Mitchell and Hovermale 1977; Droegemeier and Wilhelmson 1987; Straka et al. 1993; Bryan and Rotunno 2014a,b), but the majority of these studies are for an environment that is neutrally stratified (i.e., $\partial \theta / \partial z=0$ ). More recent studies (Liu and Moncrieff 2000; White and Helfrich 2008; Seigel and van den Heever 2012) have explored the effects of stable stratification on the density current. In an environment that has a stable layer $(\partial \theta / \partial z>0)$ beneath a neutral layer $(\partial \theta / \partial z=0)$, the depth and vertical velocity at the leading edge of the density current are reduced, but the propagation speed is increased. In a continuously stratified atmosphere $(\partial \theta / \partial z>0$ and is constant), the depth, vertical velocity at the leading edge of the density current, and propagation speed are all reduced as the stratification increased (Liu and Moncrieff 2000). The decrease in the propagation speed in a continuously stratified environment has been shown to be related to the decrease in the horizontal pressure gradient by the effects of gravity waves, which were not present in the two-layer atmosphere (Liu and Moncrieff 2000). Seigel and van den Heever (2012) showed that the propagation speed of a density current increases and its depth decreases in an environment that has a stable layer above a neutrally stratified layer.

Density currents are common at night over the Great Plains during the warm season, so understanding the effects of stable stratification and other features found in the Great Plains at 
TABLE 1. Parameters used to calculate vertical velocity from the observations in this study and density currents from previous studies. The boldface numbers indicate those that were given explicitly in previous studies. The studies denoted with an asterisk (*) in the left column denote those that are tower measurements.

\begin{tabular}{|c|c|c|c|c|c|c|c|c|c|}
\hline & $\theta^{\prime}(\mathrm{K})$ & $\bar{\theta}(\mathrm{K})$ & $H(\mathrm{~m})$ & $\alpha_{\min }\left({ }^{\circ}\right)$ & $\bar{\alpha}\left({ }^{\circ}\right)$ & $\alpha_{\max }\left({ }^{\circ}\right)$ & $\begin{array}{c}W \text { observed } \\
\left(\mathrm{m} \mathrm{s}^{-1}\right)\end{array}$ & $\begin{array}{c}W \text { estimated } \\
\left(\mathrm{m} \mathrm{s}^{-1}\right)\end{array}$ & $\begin{array}{c}\text { Percentage } \\
\text { difference }(\%)\end{array}$ \\
\hline \multicolumn{10}{|l|}{ This study } \\
\hline UW-SPARC & -5 & 312 & 1200 & 31 & 35.3 & 36.6 & 8 & 7.9 & 0.8 \\
\hline TWOLF & -7 & 310 & 1300 & 38.6 & 46.6 & 53.6 & 13 & 12.3 & 5.3 \\
\hline RaXPol & -7 & 310 & 900 & 30.8 & 35.9 & 36 & 8 & 8.23 & 3.4 \\
\hline \multicolumn{10}{|l|}{ Observations } \\
\hline Charba (1974)* & -5 & 298 & 444 & 18.7 & 20.5 & 23 & 2.5 & 3.0 & 18 \\
\hline Goff (1976; his Fig. 3$)^{*}$ & -4 & 299 & 450 & 39.6 & 40.9 & 45.8 & 4 & 5.0 & 22.8 \\
\hline Wakimoto (1982; his Case C) & -4 & 297.91 & 1100 & 23.1 & 30.4 & 33 & 6 & 6.1 & 1.5 \\
\hline Shapiro $(1984)^{*}$ & -6 & 297 & 300 & 40.5 & 40.6 & 43.8 & 5 & 5.0 & 0.4 \\
\hline Mueller and Carbone (1987) & -2.6 & 314.8 & 1600 & 37.9 & 51.1 & 61.4 & 7.9 & 8.9 & 11.5 \\
\hline Weckwerth and Wakimoto (1992) & -6 & 300 & 1400 & 37.3 & 39.8 & 43.7 & 6 & 10.6 & 55.5 \\
\hline Geerts et al. (2006; their Fig. 8) & -3.5 & 307 & 850 & 35.8 & 46.8 & 58.6 & 8 & 7.1 & 11.8 \\
\hline \multicolumn{10}{|l|}{ Simulations } \\
\hline $\begin{array}{l}\text { Droegemeier and Wilhelmson (1987; } \\
\text { their Fig. 7c) }\end{array}$ & -2 & 300 & 2600 & 24.5 & 27.3 & 44.5 & 6 & 6 & 0.3 \\
\hline Straka et al. (1993; Fig. 2) & -7 & 300 & 1300 & 22 & 31 & 57.3 & 7 & 8.9 & 23.7 \\
\hline Liu and Moncrieff (2000) & -3 & 300 & 1400 & 17.6 & 27.9 & 38.3 & 5 & 5.5 & 9.2 \\
\hline Seigel and van den Heever (2012) & -4 & 300 & 1100 & 38 & 45 & 51 & 6 & 8.5 & 34.3 \\
\hline Davies-Jones and Markowski (2013) & -8 & 300 & 3000 & 62.8 & 65.8 & 71.2 & 20 & 25.6 & 24.4 \\
\hline $\begin{array}{l}\text { Bryan and Rotunno (2014b; } \\
\text { their Fig. 3a) }\end{array}$ & $-\mathbf{3}$ & 300 & 500 & 30 & 38 & 45 & 3.5 & 4.3 & 20.8 \\
\hline $\begin{array}{l}\text { Bryan and Rotunno (2014b; } \\
\text { their Fig. 3b) }\end{array}$ & $-\mathbf{3}$ & 300 & 700 & 48 & 53 & 59 & 6.4 & 6.6 & 3.4 \\
\hline $\begin{array}{l}\text { Bryan and Rotunno (2014b; } \\
\text { their Fig. 3c) }\end{array}$ & $-\mathbf{3}$ & 300 & 760 & 54 & 61 & 65 & 7.7 & 7.6 & 1.9 \\
\hline $\begin{array}{l}\text { Bryan and Rotunno (2014b; } \\
\text { their Fig. 3d) }\end{array}$ & $-\mathbf{3}$ & 300 & 890 & 82 & 83 & 86 & 11.5 & 9.3 & 21.4 \\
\hline
\end{tabular}

night (such as vertical wind shear associated with the nocturnal low-level jet) have on density currents are important to further our understanding of the initiation and maintenance of nocturnal convective systems. The Plains Elevated Convection At Night (PECAN; Geerts et al. 2017) field project was conducted from 1 June to 15 July 2015, and had five focus areas: convection initiation (CI), atmospheric bores, the nocturnal low-level jet (LLJ), MCS structure and dynamics, and storm- and mesoscale predictability. On 15 July 2015 during intensive observing period (IOP) 30, three mobile instruments recorded the vertical velocity at the leading edge of a density current. Two of these platforms recorded an $8 \mathrm{~m} \mathrm{~s}^{-1}$ maximum vertical velocity and the third recorded a $13 \mathrm{~m} \mathrm{~s}^{-1}$ maximum vertical velocity. Vertical velocities as strong as $13 \mathrm{~m} \mathrm{~s}^{-1}$ are not commonly associated with most observed density currents (see Table 1 and references within).

The high-resolution observations of these density currents provide an opportunity to analyze the vertical velocity at the leading edge of these density currents. The purpose of this paper is to estimate the maximum vertical velocity at the leading edge of a density current using characteristics of the density current including its height, slope of the density current head, and potential temperature perturbation, and to compare the results of this method to numerical simulations as well as density currents with vertical velocity observations documented in previous studies. We start the comparison with density currents in numerical simulations because that will provide us all of the variables that we need to test the applicability of the method in controlled environments. We then test the method on the observed density current in PECAN and density currents from previous studies.

To our knowledge, this is the first study that describes the maximum vertical velocity at the leading edge of the density current as a function of the slope of the density current head.

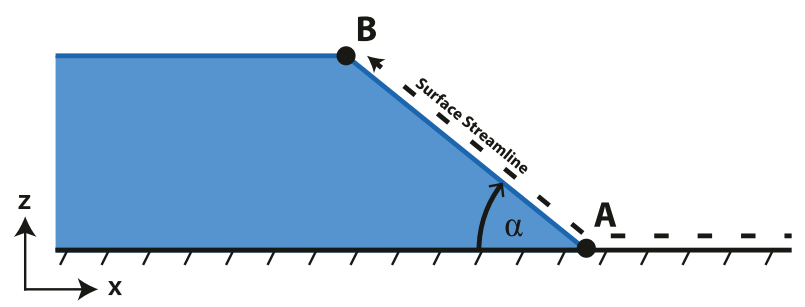

FIG. 2. Points along the streamline for the vertical velocity derivation. $\alpha$ is the slope angle of the streamline (taken to be the density current head). 


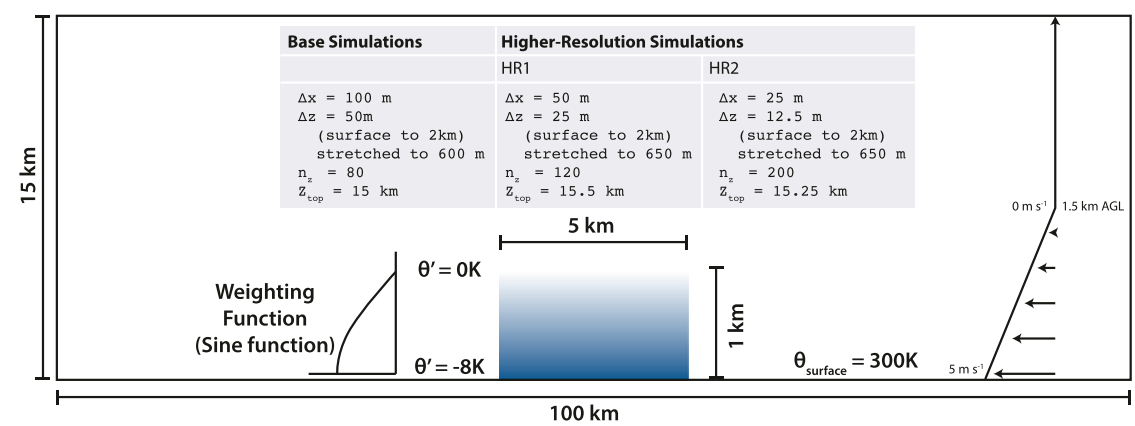

FIG. 3. Initial conditions for the numerical simulations. The blue rectangle represents the initial cold block. The model specifications for the base simulations (which are the same as the specifications for the simulations that include vertical wind shear) and the higher-resolution simulations are listed in the upper portion of the figure. The vertical wind shear for the simulations that include vertical wind shear is denoted on the right side of the figure. Section 3 provides further description of this figure.

This study also investigates how increasing static stability (as is common at night) affects the vertical velocity at the leading edge of the density current. Section 2 presents the derivation of the vertical velocity at the leading edge. This method of vertical velocity estimation is compared with the vertical velocity obtained from idealized numerical experiments in section 3. Section 4 discusses the potential for convection initiation associated with density currents. In section 5 the vertical velocity is estimated at the leading edge of density currents observed during PECAN and those documented in previous studies, and in section 6 we summarize our findings and conclusions.

\section{Vertical velocity derivation}

We derive the maximum vertical velocity at the leading edge of a density current using the theoretical propagation speed of a density current and Bernoulli's principle. The propagation speed of a density current can be described using the following equation $^{2}$ :

$$
c_{\text {density }}=K \sqrt{g D \frac{\rho_{2}-\rho_{1}}{\rho_{1}}} \approx K \sqrt{g D \frac{\theta^{\prime}}{\bar{\theta}}},
$$

where $c_{\text {density }}$ is the speed of the density current, $K$ is the internal Froude number (typically varies between 0.7 and 1.4; Wakimoto 1982), $g$ is the acceleration due to gravity $\left(9.81 \mathrm{~m} \mathrm{~s}^{-2}\right)$, $D$ is the depth of the cold fluid far behind the leading edge of the density current (see Fig. 1), $\rho_{2}$ is the density of the air inside the density current, $\rho_{1}$ is the density of the environmental air, $\theta^{\prime}$ is the potential temperature perturbation, and $\bar{\theta}$ is the mean potential temperature in the environment. A range in estimates of the speed of a density current is found using different values

\footnotetext{
${ }^{2}$ Equation (1) is valid for two-dimensional, two-layer, inviscid flows (Benjamin 1968) and while it does not account for all of the effects that affect the speed of density currents (such as hydrometeor loading and environmental vertical wind shear) it provides a simple expression for the propagation speed of a density current.
}

of $K$ with all other parameters held fixed, but the observed speeds typically fall within this range (e.g., Wakimoto 1982; Weckwerth and Wakimoto 1992).

If one assumes that the density current is a material surface (i.e., the density current is an impenetrable object of a constant potential temperature perturbation) and the air flows up and over the density current, then one can use streamlines to diagnose that flow. For a steady, inviscid flow, Bernoulli's principle (reproduced below) is a constant:

$$
\frac{U^{2}}{2}+\frac{p}{\rho}+g z=C
$$

where $U$ is the speed along the streamline, $p$ is the pressure, $\rho$ is the density, $z$ is the height above the ground, and $C$ is a constant.

Our analysis will be conducted in a density current-relative reference frame (Fig. 2) and the maximum vertical velocity is assumed to be near the top of the density current (point B in Fig. 2), so (2) becomes

$$
\frac{1}{2} U_{\mathrm{A}}^{2}+\frac{p_{\mathrm{A}}}{\rho_{\mathrm{A}}}+g z_{\mathrm{A}}=\frac{1}{2} U_{\mathrm{B}}^{2}+\frac{p_{\mathrm{B}}}{\rho_{\mathrm{B}}}+g z_{\mathrm{B}} .
$$

Point $\mathrm{A}$ is the stagnation point of the density current, so the wind speed $\left(U_{\mathrm{A}}\right)$ is zero. That point is also at the ground, so $z_{\mathrm{A}}$ is zero. At point $\mathrm{B}$, the wind speed $\left(U_{\mathrm{B}}\right)$ is a combination of the horizontal and vertical components ( $u$ and $w$, respectively). These assumptions allow (3) to be reduced to

$$
\frac{p_{\mathrm{A}}}{\rho_{\mathrm{A}}}=\frac{1}{2}\left(u^{2}+w^{2}\right)+\frac{p_{\mathrm{B}}}{\rho_{\mathrm{B}}}+g H,
$$

where $H$ is the depth of the density current head. Wakimoto (1982) suggested that, to a good approximation, the vertical variations in density below $2 \mathrm{~km}$ AGL can be safely neglected, so density is assumed to be constant along the streamline (i.e., $\left.\rho_{\mathrm{A}}=\rho_{\mathrm{B}}=\rho\right)$.

The total pressure at point $\mathrm{A}\left(p_{\mathrm{A}}\right)$ is the sum of the base state surface pressure $\left(p_{0}\right)$ and the nonhydrostatic perturbation 

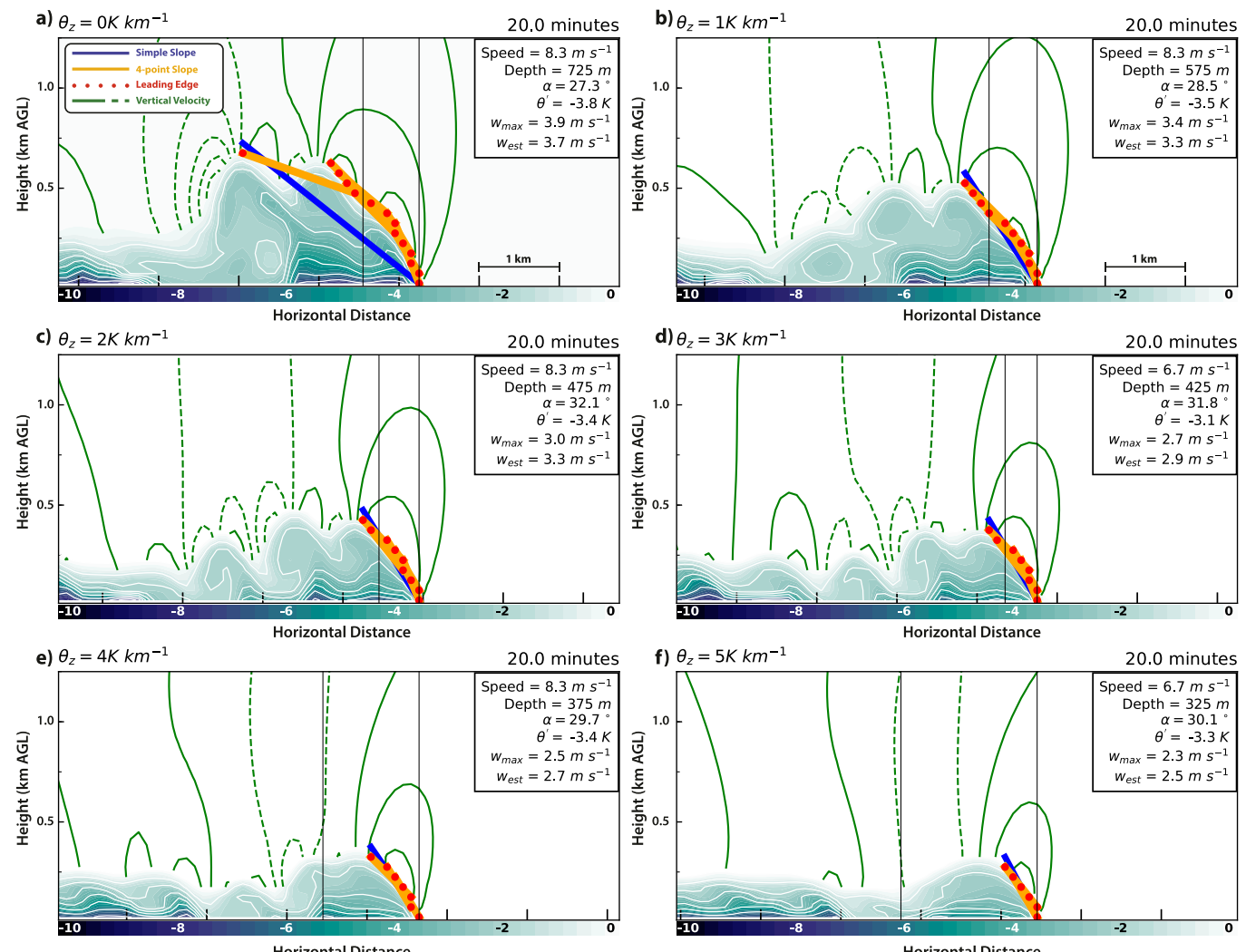

FIG. 4. Potential temperature perturbation ( $\mathrm{K}$, color-filled and white contours every $-1 \mathrm{~K}$ ) and vertical velocity $\left(\mathrm{m} \mathrm{s}^{-1}\right.$, green contours every $1 \mathrm{~m} \mathrm{~s}^{-1}$; solid contours represent updrafts) for the idealized numerical simulations at $t=20 \mathrm{~min}$. The vertical velocity inside the density current is not shown. In the upper-right corner of each panel is the speed, depth, slope angle $(\alpha)$, estimated potential temperature perturbation $\left(\theta^{\prime}\right)$, maximum vertical velocity $\left(w_{\max }\right)$ associated with the head of the density current, and the estimated maximum vertical velocity $\left(w_{\text {est }}\right)$. The solid vertical black lines represent the portion of the density current used to calculate $\theta^{\prime}$. The yellow lines represent the slopes used to create the average slope (this is the slope noted in the upper right of each panel), and the blue line is the slope using the bottom of the density current and the top of the density current. The red dots indicate the leading edge of the density current. See the legend in the upper left of (a) for a depiction of these lines.

pressure $\left(p_{\mathrm{nh}}^{\prime}\right)$. Wakimoto (1982) showed that $p_{\mathrm{nh}}^{\prime}=(1 / 2) \rho c^{2}$ where $c$ is the speed of the density current. The pressure at point $\mathrm{B}$ is related to the hydrostatic perturbation pressure $\left(p_{\mathrm{B}}=p_{0}-\int_{0}^{H} \rho g d z=p_{0}-\rho g H\right)$. Making these substitutions in (4), using Eq. (1), and simplifying yields

$$
\frac{1}{2}\left(u^{2}+w^{2}\right)=\frac{1}{2} K^{2} g \frac{\theta^{\prime}}{\bar{\theta}} H .
$$

To obtain an expression for $w$, we need a relationship between $u$ and $w$ along the streamline. Note that these relationships assume that the slope of the streamline is constant along the leading edge of the density current. Using basic trigonometry, the resulting relationship between $u$ and $w$ is $u=w / \tan (\alpha)$. Substituting this relationship into (5) yields

$$
\frac{1}{2}\left[\frac{w^{2}}{\tan ^{2}(\alpha)}+w^{2}\right]=\frac{1}{2} K^{2} g \frac{\theta^{\prime}}{\bar{\theta}} H .
$$

Solving (6) for $\mathrm{w}$ and noting that $1 / \tan ^{2}(\alpha)+1=\sin ^{2}(\alpha)$, we obtain the following expression:

$$
w=\sqrt{K^{2} \frac{g \theta^{\prime}}{\bar{\theta}} H \sin ^{2}(\alpha)} .
$$

Equation (7) relates the maximum vertical velocity at the leading edge of a density current to the density current's potential temperature perturbation, its depth, and the slope of its head. This equation is valid under two-dimensional, steady-state, and frictionless flows. The first two can be remedied by using a density-current-relative reference frame analyzed at a specific time. Some of the differences between the theoretical value of $K$ and the observed one can be attributed to friction or mixing (Haertel et al. 2001). Friction can alter the structure of the density current, especially near the surface (e.g., Charba 1974; Goff 1976; Droegemeier and Wilhelmson 1987). This equation also does not directly include the effects of environmental stratification or environmental vertical wind shear. This equation is the 

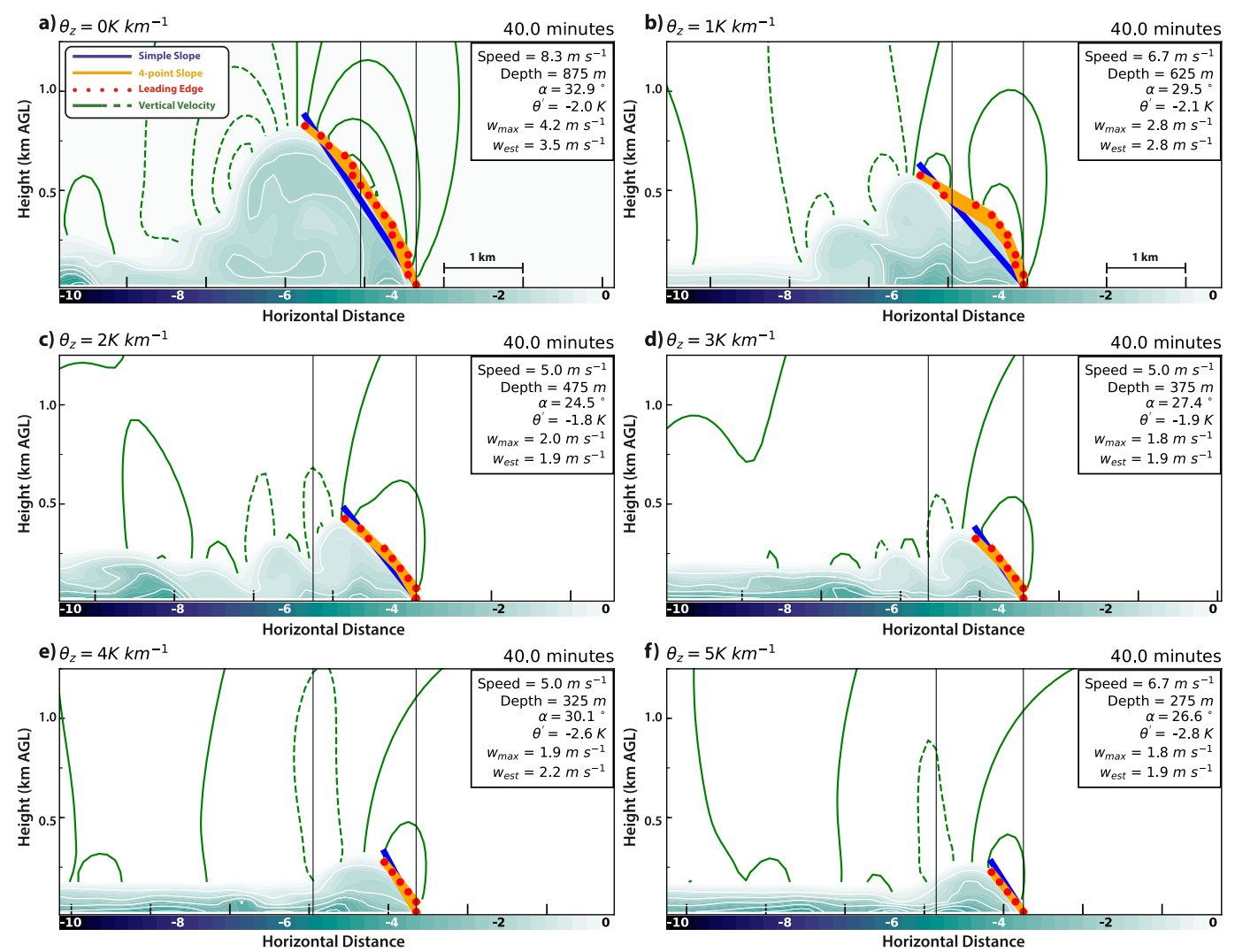

FIG. 5. As in Fig. 4, but at $t=40 \mathrm{~min}$.

simplest expression of the maximum vertical velocity at the leading edge of a density current and its applicability without explicit representation of the previously mentioned effects will be tested using two-dimensional idealized numerical simulations.

\section{Comparison with idealized numerical simulations}

These 2D idealized simulations were conducted using release 19 of Cloud Model 1 [CM1; Bryan et al. (2003)]. CM1 is a $3 \mathrm{D}$, nonhydrostatic cloud model used for idealized simulations.

\section{a. Model initial conditions}

The initial conditions are similar to those in Liu and Moncrieff (2000) with two notable exceptions: 1 ) the cold pool is not time-invariant and 2) the ambient stratification varies among the simulations. Three sets of simulations are performed: simulations in a resting base state with varying degrees of static stability (the base simulations), simulations in an environment with vertical wind shear included, and simulations with finer vertical and horizontal grid spacings.

\section{1) BASE Simulations}

The horizontal grid spacing for these simulations is $100 \mathrm{~m}$, and the vertical grid spacing is $50 \mathrm{~m}$ from the surface to $2 \mathrm{~km}$ and stretched above that to $600 \mathrm{~m}$ resolution at the model top of $15 \mathrm{~km}$ (Fig. 3). Simulations are initialized with a $5-\mathrm{km}$ wide cold block at the surface that has a $-8 \mathrm{~K}$ potential temperature perturbation that decreases sinusoidally to $0 \mathrm{~K}$ at $1 \mathrm{~km}$ above the ground. ${ }^{3}$ The model is initialized as a dry atmosphere with a resting base state and a surface potential temperature of $300 \mathrm{~K}$ (outside of the cold block). Rayleigh damping (toward the base state) was applied at a height of $10 \mathrm{~km}$ and above. Six base simulations are performed, all of which are identical except that the environmental stratification differs among them. These environmental stratifications (constant $\partial \theta / \partial z$ ) are 0 (neutrally stratified), $1,2,3,4$, and $5 \mathrm{~K} \mathrm{~km}^{-1}$.

\section{2) High-RESOLUTION SIMULATIONS}

The model setup for these high-resolution simulations are identical to that in the base simulations except the grid spacing is finer. One set of high-resolution simulations had $50 \mathrm{~m}$ horizontal grid spacing and $25 \mathrm{~m}$ vertical grid spacing from the surface to $2 \mathrm{~km}$ AGL. The other set of high-resolution simulations had a $25 \mathrm{~m}$ horizontal grid spacing and a $12.5 \mathrm{~m}$ vertical grid spacing from the surface to $2 \mathrm{~km}$ AGL. See Fig. 3 for more information about these simulations.

\footnotetext{
${ }^{3}$ Simulations that were initialized with a uniform cold block were also conducted. The time evolution of the density current and the vertical velocity pattern were similar to those of the density currents initialized with a sinusoidal cold block.
} 
TABLE 2. Froude number analysis $20 \mathrm{~min}$ into the numerical simulation (no vertical wind shear).

\begin{tabular}{ccccc}
\hline \hline$\partial \theta / \partial z\left(\mathrm{~K} \mathrm{~km}^{-1}\right)$ & $K^{2}(-)$ & $K(-)$ & $\theta^{\prime}(\mathrm{K})$ & $H(\mathrm{~m})$ \\
\hline 0 & 0.76 & 0.87 & 3.8 & 725 \\
1 & 1.05 & 1.02 & 3.5 & 575 \\
2 & 1.30 & 1.14 & 3.4 & 475 \\
3 & 1.04 & 1.02 & 3.1 & 425 \\
4 & 1.65 & 1.29 & 3.4 & 375 \\
5 & 1.28 & 1.13 & 3.3 & 325 \\
\hline
\end{tabular}

\section{3) Simulations THAT INCLUDE VERTiCAL} WIND SHEAR

These simulations are identical to the base simulations except there is vertical wind shear. The surface wind speed is $5 \mathrm{~m} \mathrm{~s}^{-1}$ directed into the density current and that wind speed decreases linearly to $0 \mathrm{~m} \mathrm{~s}^{-1}$ at $1.5 \mathrm{~km}$ AGL.

\section{b. Estimation of variables}

To calculate the slope of the density current head, the leading edge was found at every vertical grid point within the cold pool depth indicated by the location of the first point where $\theta^{\prime}$ is less than $-0.1 \mathrm{~K}$ (when iterating from the environment toward the density current; indicated by the red dots in Fig. 4). The slope was then computed using a fourpoint running average along the leading edge of the density current. For example, the slope of the points 1 to 4 was calculated, and then the slope of points 2 to 5 was calculated, and so on until the top of the density current. Those slopes were then averaged together to obtain the average slope of the density current head.

The potential temperature perturbation was more difficult to estimate. Previous studies have used the surface $\theta^{\prime}$, but in some of our simulations, the minimum $\theta^{\prime}$ was not at the surface. This elevated maximum in $\theta^{\prime}$ typically occurred later in the simulations (see Fig. 5a) and the maximum occurs near the center of the circulation within the density current head. To estimate $\theta^{\prime}$, the head of the density current was identified (see vertical black lines in Fig. 4). This was achieved by computing $\partial^{2} H(x) / \partial x^{2}$, where $H(x)$ is the height of the density current at point $x$ and designating a threshold value representative of the location of the head of the density current. For these simulations, the first value of $\partial^{2} H(x) / \partial x^{2}>25$ behind the leading edge of the density current was used to identify the density current head. Once the density current's head was identified, $\theta^{\prime}$ was averaged from the surface to $200 \mathrm{~m}$ AGL.

\section{c. Estimation of the Froude number}

The choice of the Froude number for most density current applications ranges from 0.7 to 1.4 , which results in a range for the theoretical estimate of density current's speed (e.g., Droegemeier and Wilhelmson 1985; Weckwerth and Wakimoto 1992). We take this opportunity to evaluate the Froude number from each simulation $20 \mathrm{~min}$ after the simulation began (Table 2). Given the speed of the density current, the Froude number is estimated from a rearrangement of (1). The computed Froude number ranges from 0.87 in the neutrally stratified environment to 1.29 in the $4 \mathrm{~K} \mathrm{~km}^{-1}$ stratified a) Density Current Position

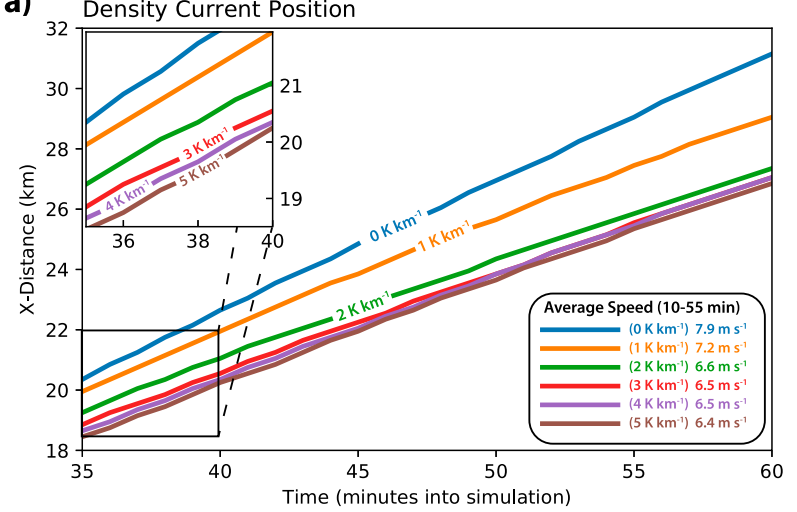

b) Density Current Depth

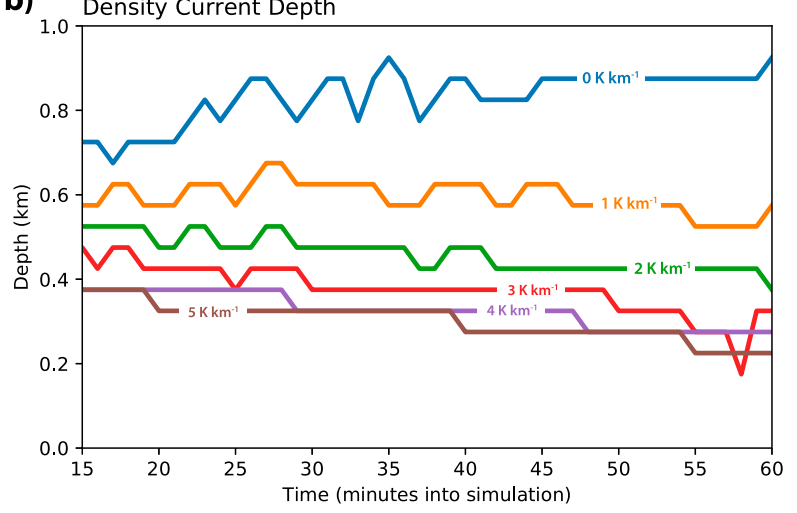

FIG. 6. (a) Density current position as a function of time. Region $35-40 \mathrm{~min}$ is enlarged in the inset and (b) density current depth $(\mathrm{km})$ as a function of time. The colored lines represent the density currents in different environmental stratifications. In (a), the average speed of the density current between 10 and 55 min into the simulation is given in the lower right.

environment, consistent with the values obtained in previous studies (e.g., Wakimoto 1982; Weckwerth and Wakimoto 1992). A Froude number of 0.85 was chosen for all numerical simulations in this study because that value resulted in the smallest difference between the observed and estimated maximum vertical velocity. This value is lower than the computed Froude number likely due to the estimate of $\theta^{\prime}$. The potential temperature perturbation was computed using an average in the lowest $200 \mathrm{~m}$ of the density current head. Due to this vertical averaging of $\theta^{\prime}$, the calculated $\theta^{\prime}$ is typically less negative than $\theta^{\prime}$ at the surface. Because $\theta^{\prime}$ appears in the denominator of a rearrangement of (1), a lower $\theta^{\prime}$ (i.e., more positive) results in a higher computed Froude number.

\section{d. Simulation results: Varying stratification}

Twenty minutes into the simulations, there was little variation in the slope angles and the perturbation potential temperatures among the density currents (Fig. 4). Forty minutes into the simulations, the depths of the density currents in the presence of weaker stratification increased while the depth of the density currents in the presence of stronger stratification decreased (Figs. 5, 6). As time progressed in the simulations, the density currents in environments with stronger stratifications 

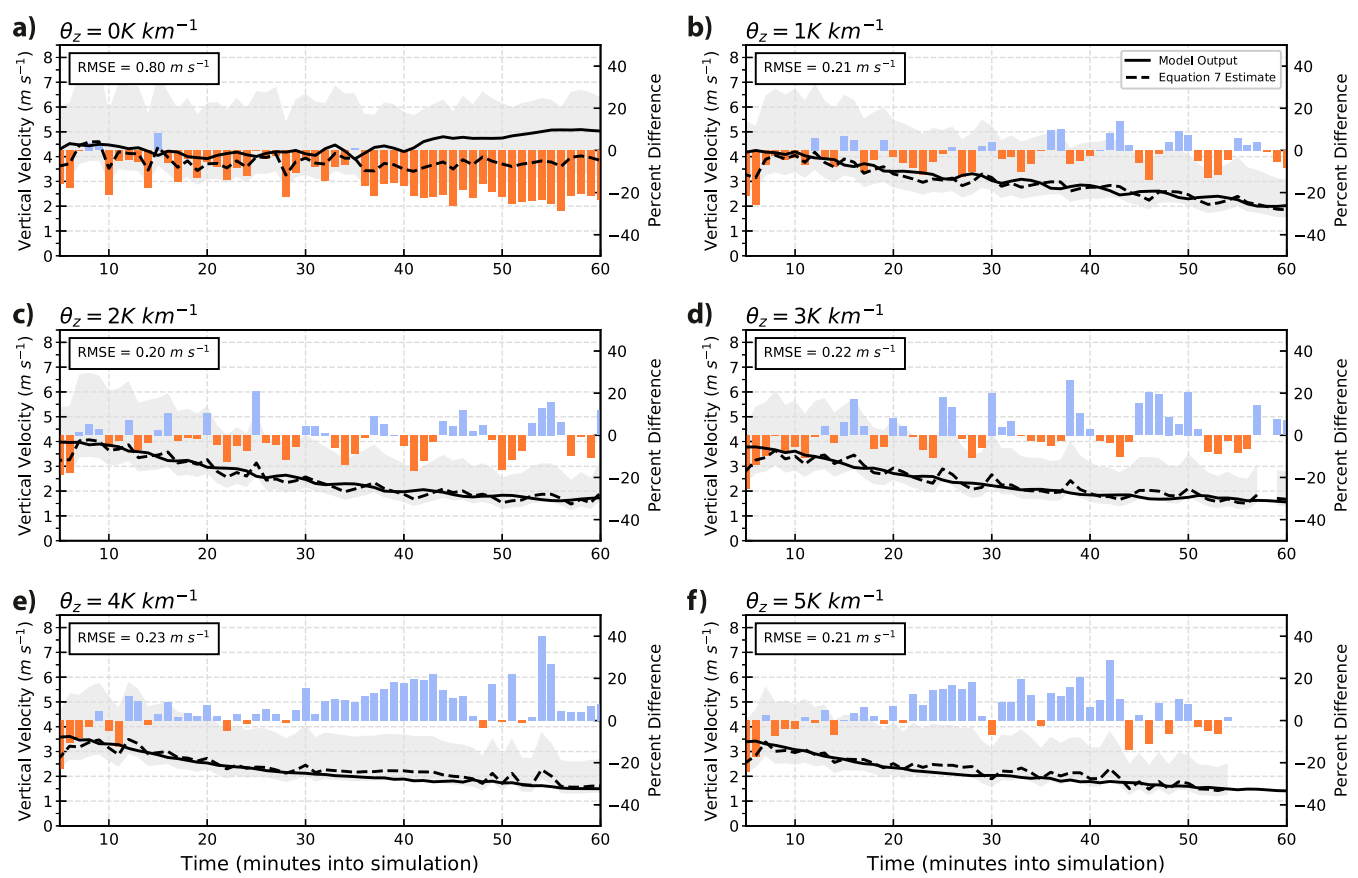

FIG. 7. Maximum vertical velocity at the leading edge of the density current (solid line) and the maximum vertical velocity estimated using (7) (dashed line) for (a) neutral stratification and (b) 1, (c) 2, (d) 3, (e) 4, and (f) $5 \mathrm{~K} \mathrm{~km}^{-1}$ stratification. The orange (downward-directed) and blue (upward-directed) bars represent the percentage difference between the model output vertical velocity and that estimated using (7). The orange bars denote an underestimate and the blue bars denote an overestimate. The gray shading represents the vertical velocity calculated between the minimum Froude number (0.7071) and the maximum Froude number (1.414) while the solid line represents the vertical velocity calculated with $K=0.85$. The RMSE for each simulation (taken from $t=10$ to $60 \mathrm{~min}$ ) is denoted in the upper left of each panel.

tended to slow down and become shallower (Fig. 6), which compares well with the results of Liu and Moncrieff (2000) and Seigel and van den Heever (2012).

The perturbation potential temperature of the density currents decreased as time progressed in all simulations, except for the density currents in the 4 and $5 \mathrm{~K} \mathrm{~km}^{-1}$ environmental stratifications (Figs. 4, 5). There is a tendency for the density current to achieve a well-mixed $\theta^{\prime}$ inside its head as the simulation progresses. The density currents in the weaker stratifications tend to achieve this well-mixed $\theta^{\prime}$ faster than those in the more strongly stratified environments. After $40 \mathrm{~min}$ into the $0 \mathrm{~K} \mathrm{~km}^{-1}$ simulation, the underestimate in the maximum vertical velocity is likely due to the weak $\theta^{\prime}$ later in the simulation. The $\theta^{\prime}$ within the density current head becomes more well-mixed (i.e., the maximum $\theta^{\prime}$ is located in the center of the density current head, so taking an average from the surface aloft can result in an underestimate of $\theta^{\prime}$ ). Vertical mixing decreases as the stratification increases, so this underestimate in $w$ is reduced as the stratification increases.

In our simulations the maximum vertical velocity at the leading edge of the density current decreased as stratification increased (Fig. 6). This decrease in the vertical velocity can be explained because more energy is required to displace a parcel upward in a stable environment than in a less stable one. The speed noted in the upper-right portions of each panel in Figs. 4 and 5 do not necessarily reflect this decrease. The speeds were calculated using the boundary of the density current (denoted by the red dots) at the lowest model level from time $t-1$ to time $t$. The coarser grid spacings can cause this boundary to "jump" to the next time, resulting in periods of faster or slower movement between those two times. Figure 6 better represents the decrease in speed as the environmental stratification is increased where the slope of the lines in Fig. 6a represent the density current speed.

Equation (7) underestimated the density current's vertical velocity in the neutrally stratified atmosphere and an overestimated the density current's vertical velocity in the more stably stratified atmospheres (especially with the 4 and the $5 \mathrm{~K} \mathrm{~km}^{-1}$ stratifications; Fig. 7). The overestimates in $w$ are likely the result of errors in the estimate of the density current's slope and because density currents in stronger stratifications have larger potential temperature deficits than those in environments with weaker stratifications. After $40 \mathrm{~min}$, the slope estimates are too high because there are a few points near the surface where the slope of the density current is $90^{\circ}$ (note the vertically stacked red dots in Figs. 5c-e) and fewer points in the vertical due to the shallower density current. The fewer vertical grid points and the $90^{\circ}$ slopes near the surface due to the algorithm results in a higher estimate of the slope angle. Because the simulated density currents were often shallower in environments with stronger stratifications, the errors when 

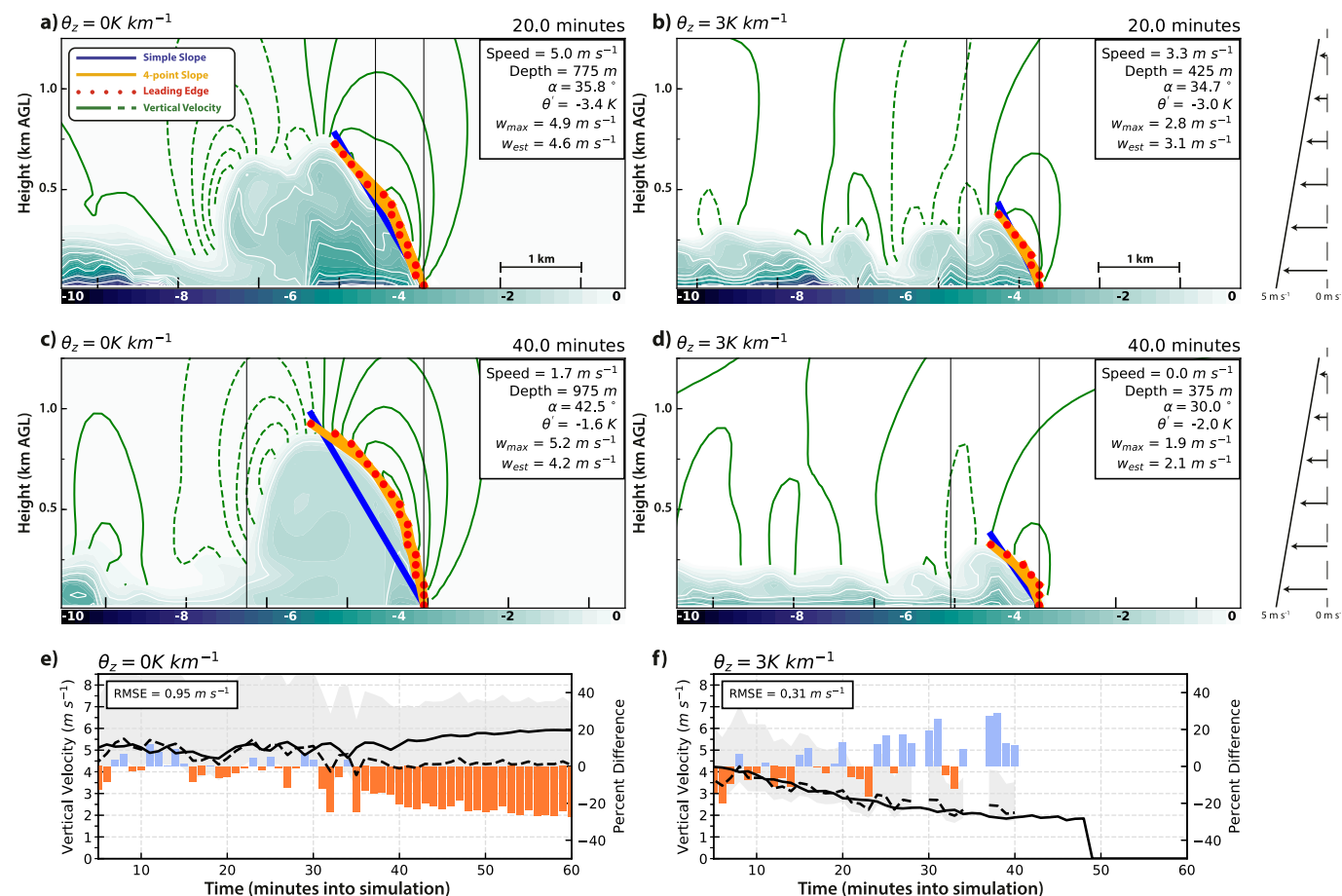

FIG. 8. (a)-(d) As in Fig. 4, but for environments with vertical wind shear $\left[5 \mathrm{~m} \mathrm{~s}^{-1}(1.5 \mathrm{~km})^{-1}\right]$. (a) Neutral stratification and (b) $3 \mathrm{~K} \mathrm{~km}^{-1}$ stratification at $t=20 \mathrm{~min}$. (c) Neutral stratification and (b) $3 \mathrm{~K} \mathrm{~km}^{-1}$ stratification at $t=$ 40 min. (e),(f) As in Fig. 7. In (f), after 40 min, the density current becomes shallow and the method used to estimate the slope failed. In (a)-(d), the magnitude and direction of the system-relative wind is shown to the right of each row.

estimating the slope increases with increasing stratification. However, the errors typically fall within $\pm 20 \%$. The estimated maximum vertical velocity decreases with time and increasing stratification, and these decreases likely indicate that the effects of stable stratification in the environment are being indirectly accounted for [likely via the height term of Eq. (7)].

There is a periodicity in the pattern of the estimated maximum vertical velocity as a function of time (especially evident in Figs. 7b-d). This periodicity is likely related to the periodicity of the slope angle estimates (not shown). These estimates of the slope angle are related to KH billows, which alter the shape of the leading edge of the density current but do not affect the depth in these simulations. The fewer number of points in the vertical in simulations with increasing stratification makes this periodicity more evident until the condition necessary for KHI vanishes at $4-5 \mathrm{~K} \mathrm{~km}^{-1}$ stratifications.

\section{e. Simulation results: Inclusion of vertical wind shear}

The effects of environmental wind shear on the vertical velocity are not explicitly accounted for in (7). The 0 and $3 \mathrm{~K} \mathrm{~km}^{-1}$ numerical simulations were repeated with the addition of $5 \mathrm{~m} \mathrm{~s}^{-1}$ of vertical wind shear between the surface and $1.5 \mathrm{~km}$ AGL to examine the effect wind shear has on vertical velocity (the wind shear is denoted on the right in Fig. 8). The surface wind speed is $5 \mathrm{~m} \mathrm{~s}^{-1}$ (directed toward the density current), which decreases linearly to $0 \mathrm{~m} \mathrm{~s}^{-1}$ at $1.5 \mathrm{~km}$ AGL. This shear profile results in a vertical circulation that should act to increase the net vertical velocity at the leading edge of a density current (Rotunno et al. 1988). Previous studies (e.g., Droegemeier and Wilhelmson 1985; Bryan and Rotunno 2014a,b) suggest that as the environmental shear increases in a sign opposite to that of the baroclinically generated vorticity, the vertical velocity at the leading edge of a density current increases up to its maximum potential (the "optimal state" noted by Rotunno et al. 1988). The maximum vertical velocities in these simulations that include vertical wind shear have similar patterns to those in the simulations without vertical wind shear (e.g., the oscillations as a function of time in the $3 \mathrm{~K} \mathrm{~km}^{-1}$ and the shape as time progressed).

As expected, due to a more favorable RKW balance, the maximum vertical velocities were greater than those in the noshear simulations. A similar increase (decrease) in the depth of the density current in the weaker (stronger) environmental stratification occurs in the simulations that include vertical wind shear, and the depth of both density currents is larger than those in the no-shear environments (Fig. 8). The estimate of the maximum vertical velocity for these simulations that include vertical wind shear corresponds well to that of the model output maximum vertical velocity. This close correspondence indicates that Eq. (7) indirectly accounts for the effects of vertical wind shear likely through the height and slope variables.

\section{f. Simulation results: Sensitivity to grid spacing}

The characteristics of the density current in the higherresolution simulations as a function of time (see Fig. 3 for 

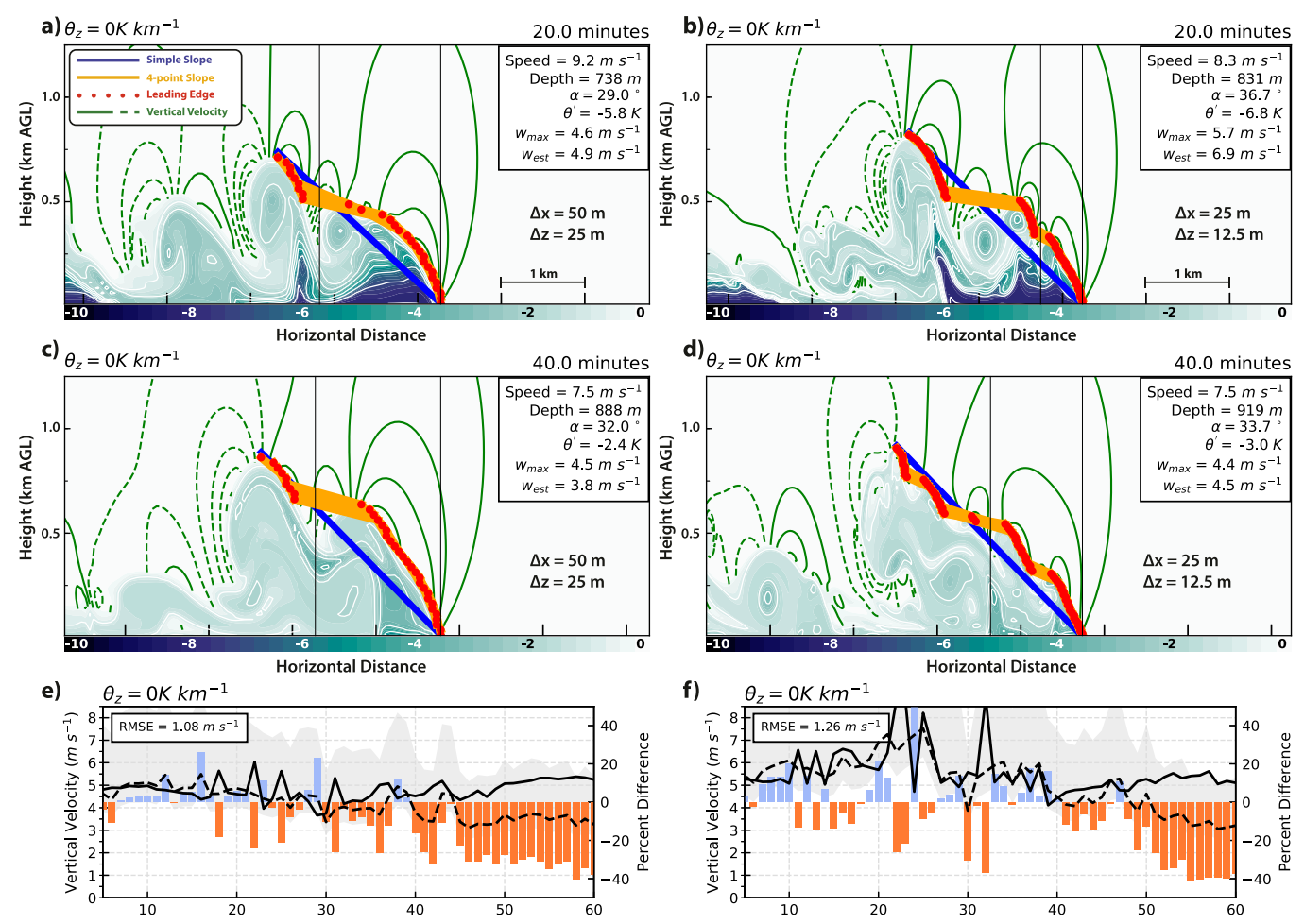

FIG. 9. As in Fig. 8, but for different model grid spacings: (a),(c),(e) $50 \mathrm{~m}$ horizontal grid spacing and $25 \mathrm{~m}$ vertical grid spacing and (b),(d),(f) $25 \mathrm{~m}$ horizontal grid spacing and $12.5 \mathrm{~m}$ vertical grid spacing.

resolution specifications) are similar to those in the lowerresolution simulation. For example, in both the high-resolution simulation and the lower-resolution simulations, the depth of the density current increases between 20 and 40 min into the simulation and $\theta^{\prime}$ becomes more uniform in the head of the density current as time progresses (Fig. 9). While the time evolution of the density currents may be similar, characteristics of the density current at any given time may look very different compared to those in the low-resolution simulations. For example, smaller-scale features such as $\mathrm{KH}$ billows are better resolved in these simulations, resulting in a slightly higher and more irregular vertical velocity pattern as a function of time (Figs. 9e,f).

The RMSE for these simulations is larger than that of the low-resolution simulations, but the errors in the estimates as a function of time are similar to those for the low-resolution simulation (Figs. 9e,f). Early in the simulations, the estimated and model-output vertical velocity are similar and later in the simulations, there is an underestimate in the estimated vertical velocity. The estimated maximum vertical velocity seems to capture some of the irregularities seen in Fig. 9f. For example, the vertical velocity increases during the first $25 \mathrm{~min}$ of the simulation, then levels off at a lower value. The estimate using Eq. (7) captures this overall trend (though there is still an overall underestimate after $40-45 \mathrm{~min}$ like in the previous simulations). Because the algorithm used to compute the slope of the density current uses the depth of the density current, a $\mathrm{KH}$ billow is occasionally captured. Owing to the similar slope angle of the billow region to the head and the high number of vertical grid points, it is unlikely that this billow will create a significant difference in the slope of the density current head.

\section{g. Weaknesses of the equation}

Equation (7) does not account for features including, but not limited to, $\mathrm{KH}$ billows, vertical variations in static stability, and atmospheric moisture content. All of these features could affect the maximum vertical velocity at the leading edge of a density current. KH billows typically form near the top of the density current and are advected rearward (Mueller and Carbone 1987; White and Helfrich 2008), so their impact on the maximum vertical velocity at the leading edge is unclear despite their frequent occurrence with density currents. The more vertically oriented the slope, the more likely it is that the $\mathrm{KH}$ billows can impact the vertical velocity (e.g., Bryan and Rotunno 2014b; their Fig. 5b).

The equation is sensitive to the estimate of the slope angle of the density current's head, but that sensitivity could be related to the model setup and the vertical resolution of the simulation. In practice, without a vertically pointing profiling system or a range-height indicator (RHI)-style scan from radars or similar instruments, the slope of the density current is extremely hard to estimate. The method to estimate slope outlined in Hutson et al. (2019) could work, but observations of $\theta^{\prime}$ and the vertical wind shear are necessary. The range for the slopes of observed density currents seen in Table 1 suggests that a typical range is between $30^{\circ}$ and $50^{\circ}$. 
a) Shapiro (1992) Steady-State Solution

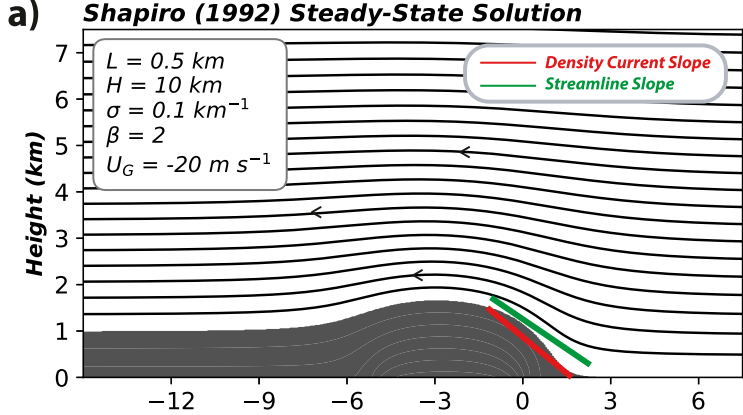

b) Streamline Analysis

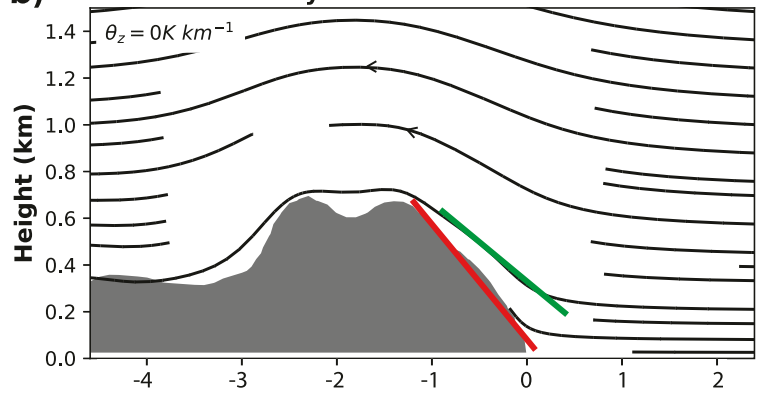

c) Streamline Analysis

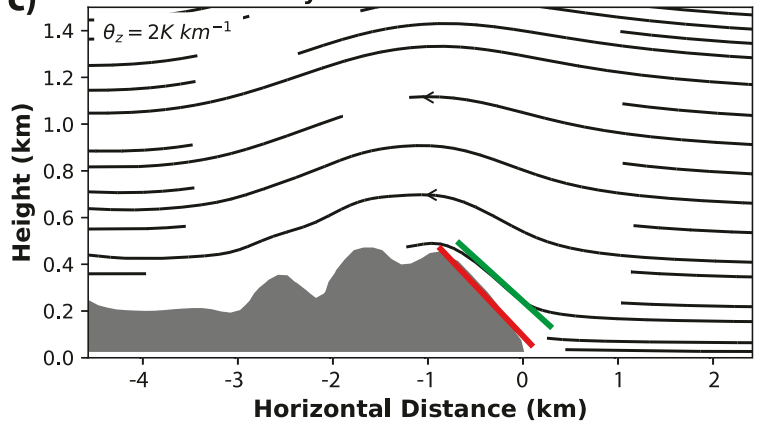

FIG. 10. $X-Z$ cross sections of streamlines over density currents (gray color-filled) in the (a) Shapiro (1992) analytical model, (b) $0 \mathrm{~K} \mathrm{~km}^{-1}$ idealized simulation, and (c) the $2 \mathrm{~K} \mathrm{~km}^{-1}$ idealized simulation. The red line represents the slope of the density current head while the green line represents the slope of a streamline near the density current head.

Despite the assumptions made, the results from all of the numerical simulations presented suggest that (7) can be used to estimate the vertical velocity at the leading edge of a density current with an accuracy of $\sim \pm 20 \%$. However, these simulated density currents are highly idealized and some atmospheric processes that affect density currents are not included (such as how the proximity to the parent MCS affects the structure of the density current; i.e., the density current could have a different shape, $\theta^{\prime}$, and propagation speed if it is closer to the MCS than one that has propagated far away). It is important to remember that this is a simple estimate of the maximum vertical velocity and (7) does not include (at least directly) effects such as environmental wind shear, varying stratification with height, and $\mathrm{KH}$ billows that can affect the

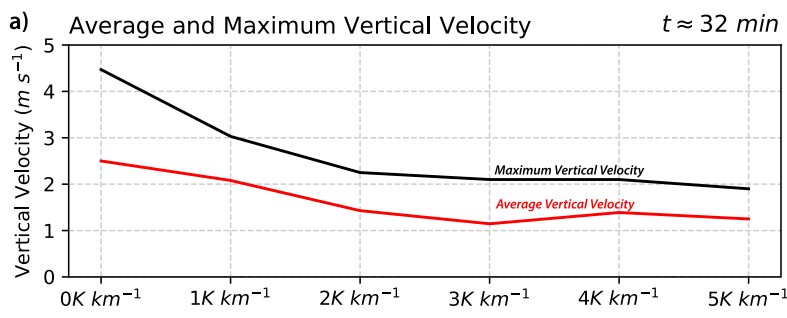

b) Ratio of Average to Maximum Vertical Velocity

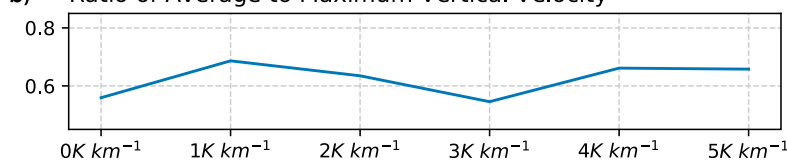

FIG. 11. (a) Maximum vertical velocity (black line) and average vertical velocity for parcels as they ascend the density current (red line) and (b) the ratio of the average vertical velocity to the maximum vertical velocity. Both panels are valid at the time the density current interacts with the passive tracers $(t \sim 32 \mathrm{~min}$ in all simulations).

vertical velocity. Overall, (7) shows promise when estimating the vertical velocity in the simulations.

\section{Implications for CI}

It has been suggested that CI by density currents is "primarily a function of horizontal convergence" (Moncrieff and Liu 1999). Stronger convergence at the leading edge of the density current results in stronger vertical velocities (due to stronger acceleration in the vertical), increasing the likelihood that CI will occur. The net displacement of air parcels in the vertical is important to CI. Typically, stronger density currents (i.e., those that are deeper and have a stronger potential temperature perturbation) induce greater lift than weaker density currents. Furthermore, environmental vertical wind shear can offset the baroclinically generated horizontal vorticity at the leading edge of a density current, resulting in a more vertically oriented updraft (Rotunno et al. 1988; Bryan and Rotunno 2014a), increasing the likelihood of CI. Hutson et al. (2019) showed that given the same environmental shear, a density current with a weaker $\theta^{\prime}$ can have a steeper slope, which could result from a more favorable RKW balance. The environment is also important to determine whether or not $\mathrm{CI}$ will occur. An environment with a lower level of free convection (LFC) will be more susceptible to CI than that with a higher LFC.

We now examine the vertical displacement of air parcels in the Shapiro (1992) analytical model and in the numerical simulations presented earlier. The Shapiro (1992) analytical model is a two-dimensional model in a steady-state, neutrally stratified, and frictionless environment. This analytical model can be used to analyze the horizontal and vertical motions over a density-current like barrier given inputs such as the vertical wind shear. The maximum net displacement of a streamline in the Shapiro (1992) analytical model was the height of the density current itself, and the vertical displacement depth is decreased for streamlines that originate above the surface (Fig. 10a). This depth does not account for gravitational instability above the density 


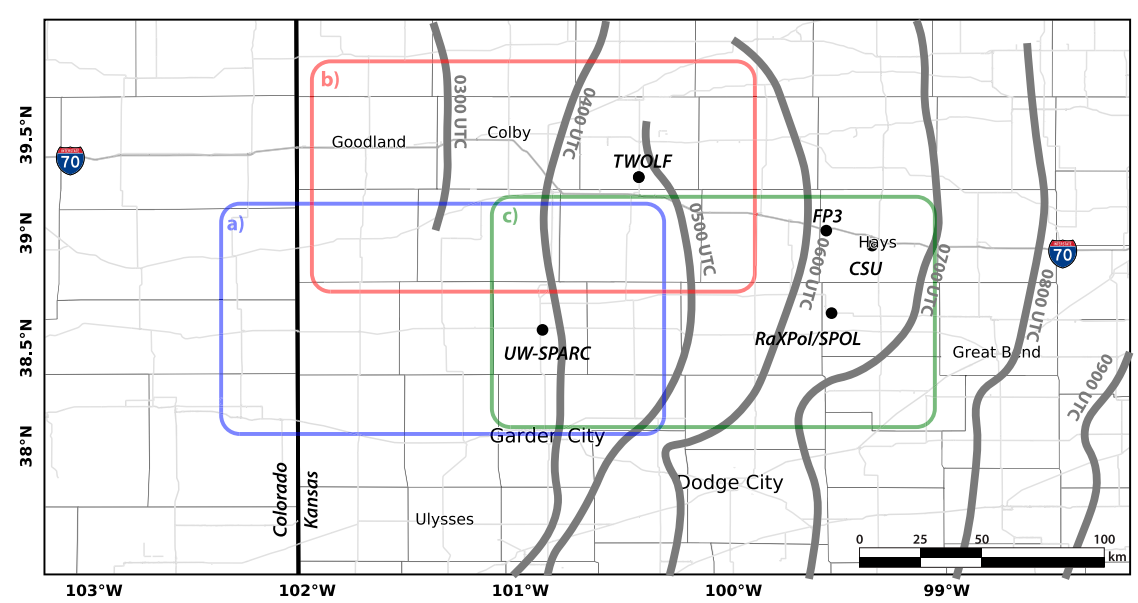

FIG. 12. Locations of instruments on 15 Jul 2015 used in this study. The gray lines denote the approximate location of the density current at the labeled time. The blue, red, and green rectangles denote the locations of the radar reflectivity images seen in Fig. 13 and the labels in the upper-left corner of those rectangles denotes its corresponding panel in Fig. 13.

current, which would result in deeper ascent nor does it account for features that promote the formation of a bore ahead of the density current (Haghi et al. 2017), which could alter the net displacement of parcels as they interact with the density current.

To examine the total lift in the numerical simulation and to compare the displacement in these simulations to that of the Shapiro (1992) analytical model, passive tracers were initialized near the surface ahead of the density current. The average vertical velocity during the tracer's ascent is calculated as the net displacement divided by duration of ascent. The average vertical velocity and the maximum vertical velocity at the time the density current interacted with the tracers are seen in Fig. 11a. The average and maximum vertical velocities decreased with increasing static stability, leveling off for lapse rates above $2 \mathrm{~K} \mathrm{~km}^{-1}$; the average vertical velocity was approximately $60 \%$ of the maximum regardless of the environmental stratification (Fig. 11b). The net displacement for tracers that originate at the surface in the neutral simulation was $\sim 750 \mathrm{~m}$ occurring over a period of $\sim 5 \mathrm{~min}$, resulting in an average ascent of $2.5 \mathrm{~m} \mathrm{~s}^{-1}$. The net displacement of the passive tracers near the surface in the simulations is approximately the depth of the density current. The net displacement of passive tracers initialized aloft (but still below the depth of the density current) was less than the depth of the density current. The maximum net displacement (in terms of depth) occurs for surface parcels and decreases for parcels that originate higher above the surface (see streamlines in Figs. 10b,c). These results are comparable to those in the Shapiro (1992) analytical model.

Davies-Jones and Markowski (2013) found that in idealized simulations the vertical displacement is sensitive to how the model is initialized. Vertical wind shear also affects the displacement of the air parcels. In the numerical simulations conducted in a neutral environment, when the shear increased toward the optimal state discussed in Rotunno et al. (1988), the parcels experienced a greater vertical displacement compared to those in an environment with no vertical wind shear, consistent with the results shown by Bryan and Rotunno (2014a). Using this method to analyze the potential for CI may be too complex. While we can estimate the net displacement of parcels by the density current head, convection initiation by density currents is governed by factors not accounted for including CAPE and CIN as a function of height (i.e., in certain environments, a parcel might require more lift than another for CI to occur), the ascent related to the density current behind the head, and mesoscale environment variations (such as convergence aloft) that could affect whether or not CI will occur.

\section{Comparisons with observations}

The vertical velocity estimates in the numerical simulations indicate that (7) works reasonably well to estimate the

TABLE 3. Specifications of instruments used in this study.

\begin{tabular}{lccc}
\hline \hline \multicolumn{1}{c}{ Instrument } & UW-SPARC & TWOLF & RaXPol \\
\hline Temporal resolution $(\mathrm{Hz})$ & 0.086 & 1 & 0.1 \\
Range resolution $(\mathrm{m})$ & 30 & 46.5 & 75 \\
Latitude $\left({ }^{\circ} \mathrm{N}\right)$ & 38.553 & 39.191 & 38.553 \\
Longitude $\left({ }^{\circ} \mathrm{W}\right)$ & 100.896 & 100.444 & 99.540 \\
Operating time $(\mathrm{UTC})$ & $0021-0529$ & $0240-0455$ & $0108-0730$ \\
Instrument type & Halo streamline Doppler lidar & Lockheed Martin windtracer & X-band polarimetric radar \\
& & Doppler lidar & \\
\hline
\end{tabular}



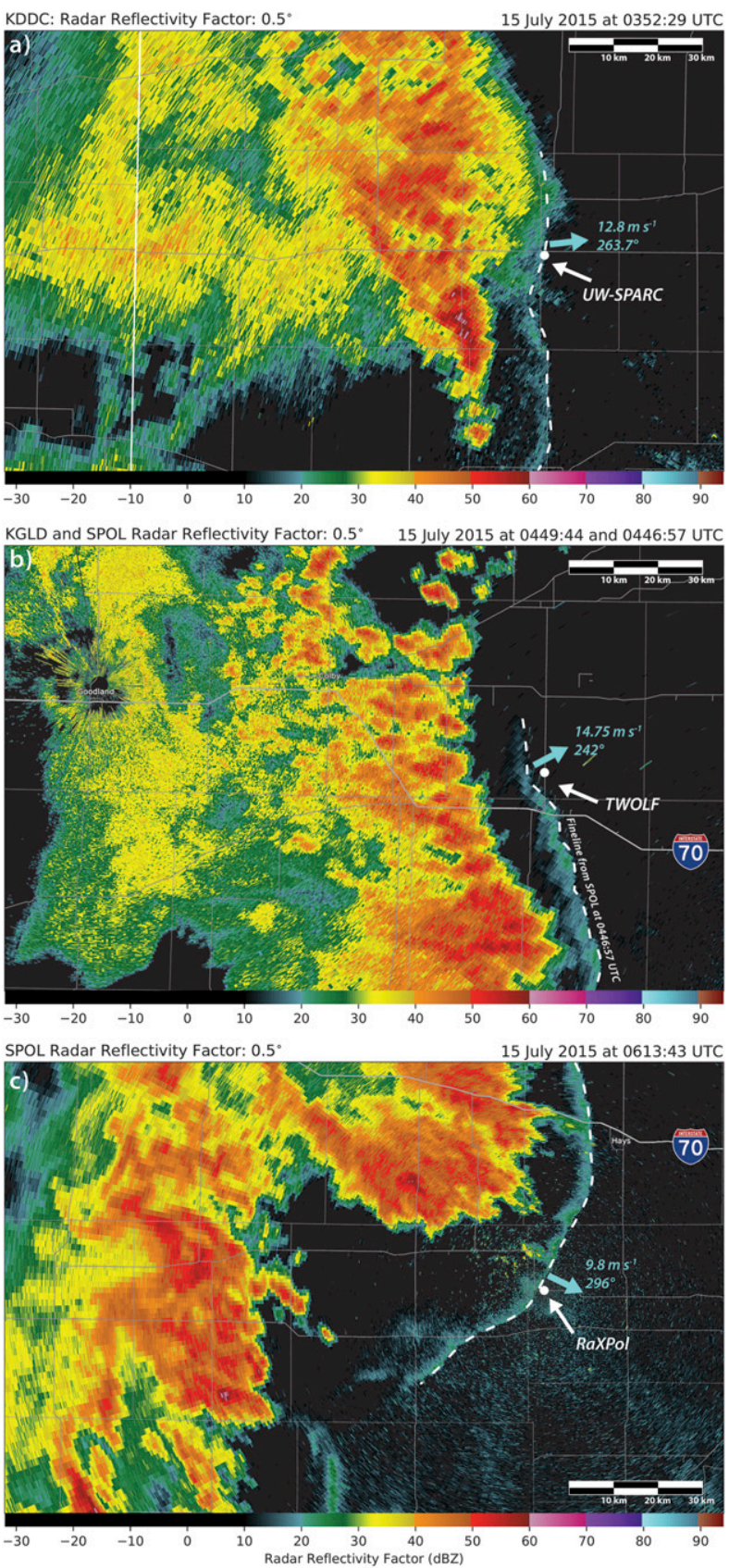

FIG. 13. Radar reflectivity factor for (a) Dodge City, Kansas (KDDC), at 0352 UTC within the blue rectangle of Fig. 12; (b) a composite of Goodland, Kansas (KGLD), and S-Pol at 0449 and 0446 UTC, respectively, within the red rectangle of Fig. 12; and (c) S-Pol at 0613 UTC within the green rectangle of Fig. 12. In (b) the convective storm is the reflectivity from KGLD at 0449 UTC while the density current is the reflectivity from S-Pol at 0446 UTC. The density current in all three panels is denoted by the dashed white line and the cyan arrow indicates the propagation direction (speed and direction estimated from radar data).
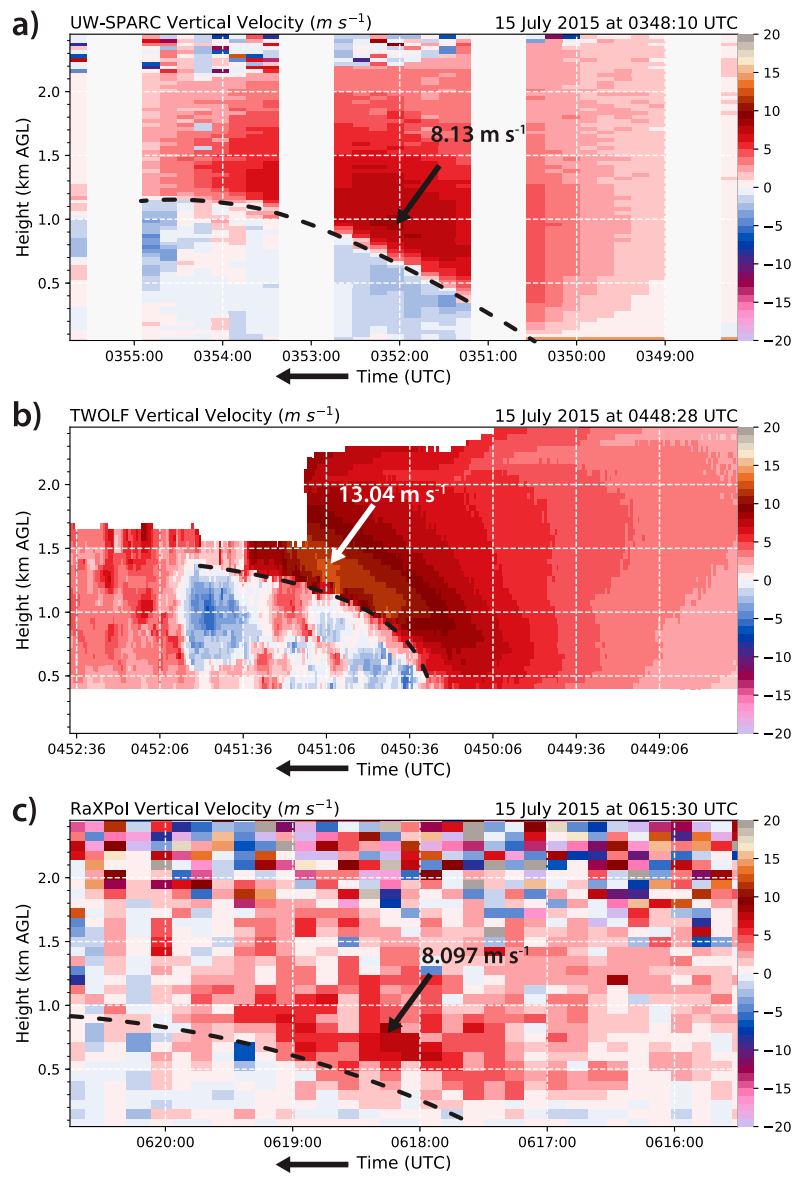

FIG. 14. Vertical velocity $\left(\mathrm{m} \mathrm{s}^{-1}\right)$ observed by (a) UW-SPARC, (b) TWOLF, and (c) RaXPol. Note that time increases from right to left. The ordinate is height above ground level. The black dashed line denotes the leading edge of the density current.

maximum vertical velocity. We now test this method on observed density currents during the PECAN field project and density currents from previous studies.

\section{a. Observed density currents during PECAN on 15 July 2015}

During the late afternoon of 14 July 2015, convective storms were initiated in the lee of the Rockies and grew upscale into an MCS that propagated eastward through the PECAN domain between 0200 and 0800 UTC 15 July 2015 (Fig. 12). This MCS produced a density current that generated an atmospheric bore ${ }^{4}$ on its southeastern side (multiple finelines appeared on the Goodland, Kansas, WSR-88D at 0400 UTC. The MCS and fine lines were also observed by

\footnotetext{
${ }^{4}$ The atmospheric bore is not the focus of this study. Ascent associated with an atmospheric bore could interfere with the vertical velocity near the density current. For that reason, this study focuses on density currents that are not associated with bores at the analysis time. For a more detailed discussion of the bores that occurred during this IOP, see Grasmick et al. (2018).
} 

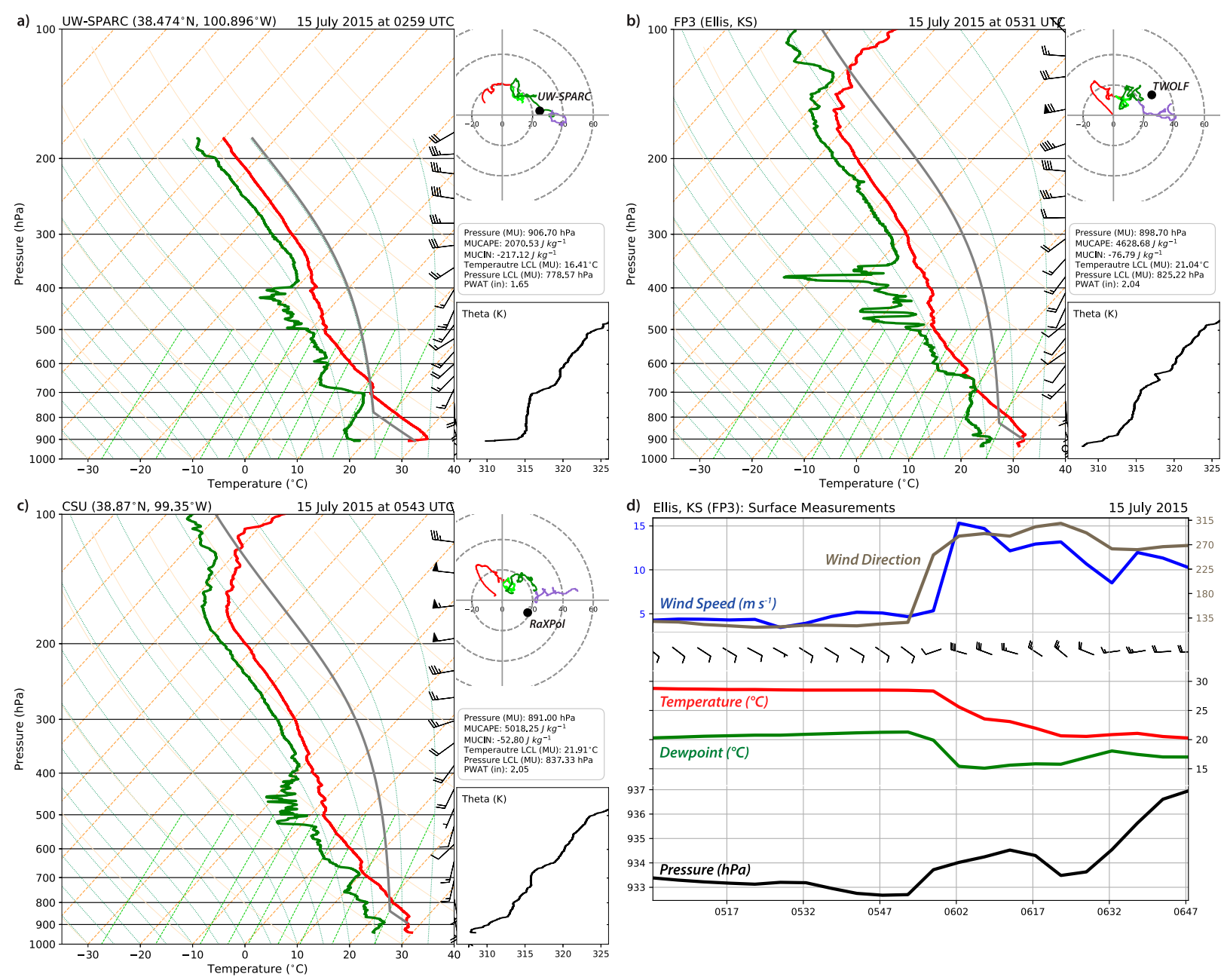

FIG. 15. Observed sounding data from (a) UW-SPARC at 0259 UTC, (b) FP3 at 0531 UTC, and (c) CSU at 0543 UTC. The speed (knots; $1 \mathrm{kt} \approx 0.51 \mathrm{~m} \mathrm{~s}^{-1}$ ) and propagation direction of the density current at each location are displayed in the hodograph. Winds below $700 \mathrm{hPa}$ are red, winds between 700 and $500 \mathrm{hPa}$ are light green, winds between 500 and $300 \mathrm{hPa}$ are dark green, and winds between 300 and $200 \mathrm{hPa}$ are purple. (d) Surface measurements from FP3 during density current passage. The blue line represents the wind speed ( $\mathrm{m} \mathrm{s}^{-1}$ ), the brown line is the wind direction, the red line is the temperature $\left({ }^{\circ} \mathrm{C}\right)$, the green line is the dewpoint $\left({ }^{\circ} \mathrm{C}\right)$, the black line is the station pressure $(\mathrm{hPa})$, and for the wind barbs, a full barb is $10 \mathrm{kt}\left(5.1 \mathrm{~m} \mathrm{~s}^{-1}\right)$ and a half barb is $5 \mathrm{kt}\left(2.57 \mathrm{~m} \mathrm{~s}^{-1}\right)$. The large black dot within the hodograph represents the density current speed at the labeled instrument location.

S-Pol radar (UCAR/NCAR-Earth Observing Laboratory 2016b; Hubbert et al. 2018). Unfortunately, many of the observing platforms were unavailable during this event as they were returning from a previous IOP in Illinois and Indiana. However, notable instruments that probed the 15 July MCS include the University of Wisconsin Space Science and Engineering Center Portable Atmospheric Research Center (UW-SPARC; Wagner et al. 2016a; Wagner et al. 2019), the Truck-Mounted Wind-Observing lidar Facility (TWOLF; Bluestein et al. 2014; Reif et al. 2016) and the rapidscan, X-band, polarimetric mobile Doppler radar (RaXPol; Pazmany et al. 2013; Bluestein and Parsons 2016) (see Table 3 for instrument specifications). The locations of these three instruments as well the Fixed PECAN Integrated Sounding Array (PISA) 3 (FP3) and the Colorado State University
(CSU) mobile PISA sounding launch locations are shown in Fig. 12.

A density current passed over UW-SPARC at $\sim 0350$ UTC, TWOLF at $\sim 0450$ UTC, and RaXPol at $\sim 0613$ UTC (Fig. 13). Vertical velocity data were collected at all three locations during the passage of each density current. TWOLF and UWSPARC had vertically pointing Doppler wind lidars, while RaXPol was collecting $180^{\circ}$ RHI scans. For these RaXPol scans, the $90^{\circ}$ elevation radial is used to obtain the vertical velocity. UW-SPARC measured an $\sim 8 \mathrm{~m} \mathrm{~s}^{-1}$ vertical velocity at the leading edge of the density current, TWOLF recorded $\sim 13 \mathrm{~m} \mathrm{~s}^{-1}$ vertical velocity, and RaXPol measured $\sim 8 \mathrm{~m} \mathrm{~s}^{-1}$ ascent (Fig. 14).

To estimate the vertical velocity of each density current using (7), the height, slope, and potential temperature perturbation 
associated with each density current must be known. The UW-SPARC released soundings prior to the density current passage (Wagner et al. 2016b, Fig. 15a) and collected surface observations, so that information will be used to obtain the parameters for that density current. There was no collocated thermodynamic information at the TWOLF or RaXPol locations. However, a sounding was released at 0531 UTC from FP3 located in Ellis, Kansas (Clark 2016, Fig. 15b), approximately $80 \mathrm{~km}$ away from TWOLF. Another sounding was launched by CSU at 0543 UTC in Hays, Kansas (Ziegler et al. 2016, Fig. 15c), approximately $40 \mathrm{~km}$ from RaXPol. These soundings (which were launched prior to the passage of the density current) are used to obtain the system-relative wind speed as a function of height, the environmental vertical potential temperature gradient, and the mean environmental potential temperature. Surface observations at FP3 are used to obtain the potential temperature perturbation after the passage of the density current at TWOLF and RaXPol (Fig. 15d). The difference in location between where FP3 was and where TWOLF and RaXPol (see Fig. 12) could result in differences in the estimates of $\theta^{\prime}$ and environmental static stability, which could introduce errors into the estimate of the maximum vertical velocity.

Previous studies (e.g., Hutson et al. 2019) estimated the slope of the density current using points at two heights (e.g., the slope is computed from 250 and $750 \mathrm{~m}$ ). However, because the density currents observed in this study are of various depths and those depths may not best represent the slope of the density current head, the slope was estimated using a few lines nearly parallel to the density current interface (see Fig. 16). These lines were then averaged together to obtain the average slope of the density current (range and average given in Table 1).

The surface potential temperature perturbation computed from the collocated surface measurements from UWSPARC is approximately $-5 \mathrm{~K}$ at UW-SPARC and $-7 \mathrm{~K}$ at TWOLF and RaXPol. The $-7 \mathrm{~K}$ perturbation is estimated from the surface measurements at FP3 (UCAR/NCAREarth Observing Laboratory 2016a; Fig. 15d). These perturbation potential temperatures compare well with atmospheric emitted radiance interfermoterer (AERI) observed potential temperature from UW-SPARC and FP3 (not shown). The height and slope of the density current are estimated using the velocity, signal-to-noise ratio (SNR), and radar reflectivity factor data when applicable (see the dashed black line in Fig. 14). The zero isodop was used to identify the approximate location of the density current and the boundary between high and low SNR or highto-low radar reflectivity factor was used to refine the location. A time-to-space conversion using the radar-estimated density current speed to obtain the horizontal distance.

A schematic of each density current, thermodynamic information, system-relative wind speed, and slope is shown in Fig. 16. Using these parameters, a maximum vertical velocity estimate of $7.9 \mathrm{~m} \mathrm{~s}^{-1}$ is obtained for the UW-SPARC density current, $12.3 \mathrm{~m} \mathrm{~s}^{-1}$ for the TWOLF density current, and $8.2 \mathrm{~m} \mathrm{~s}^{-1}$ for the RaXPol density current assuming a density current height of 1200,1300, and $900 \mathrm{~m}$, respectively (see Figs. 14 and 16 and Table 1). These estimates are within $\pm 6 \%$ of the observed vertical velocity. Another possible reason for
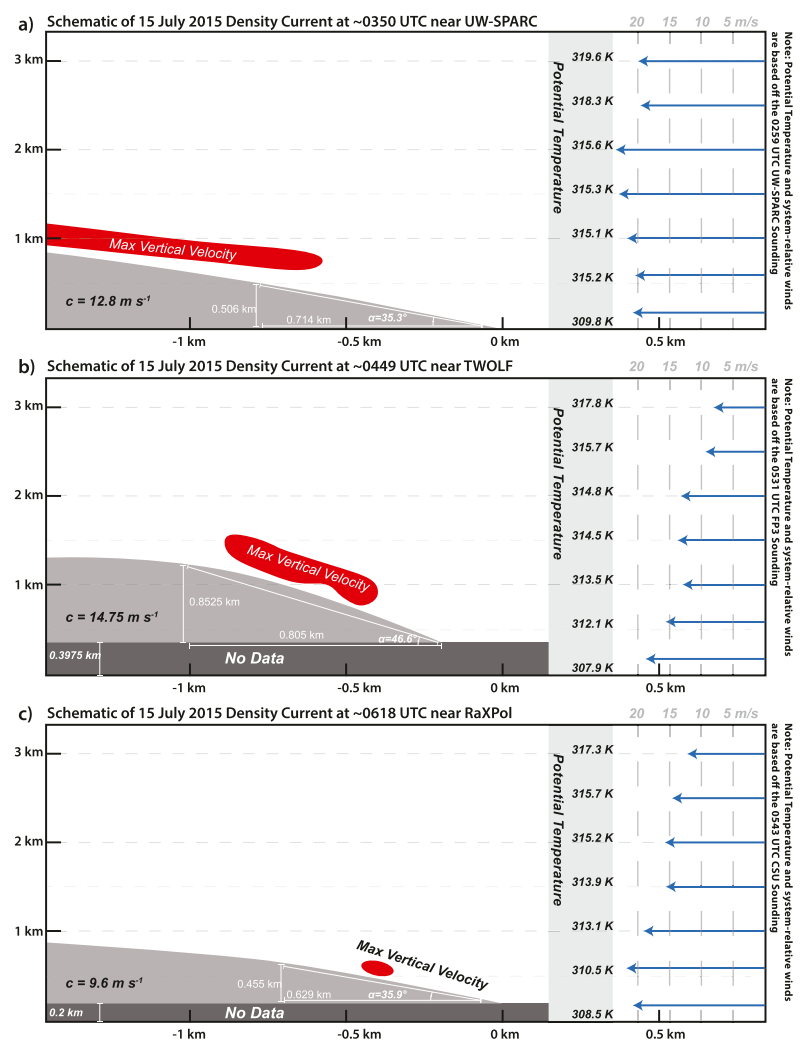

FIG. 16. Schematic of the density current observed at (a) UWSPARC, (b) TWOLF, and (c) RaXPol. The horizontal distance was determined using a time-to-space conversion using the speed of the density current (seen on the left side of the density current in each panel). The potential temperature and system-relative wind speeds (blue arrows, $\mathrm{ms}^{-1}$ ) are shown on the right side of each panel and are determined from the soundings in Fig. 15.

the higher vertical velocity associated with the TWOLF density current is a more favorable RKW balance (see system-relative winds in Fig. 16), resulting in a more vertically oriented updraft (and subsequently higher vertical velocity) than that at the other two locations. The convection remained more intense in northern Kansas (where TWOLF was) and decayed in southern Kansas as the night progressed. This more favorable RKW balance and the stronger updraft at the leading edge of the density current could have maintained the MCS in northern Kansas better.

\section{b. Comparison with previously studied density currents}

For a more complete test of this method, we will look at previously documented density currents that include vertical velocity data (from observations or numerical simulations) and apply (7). For many of these cases, the parameters are estimated with more uncertainty, since many of these studies do not include direct information about the slope of the density current or its height, the system-relative wind speed, and/or the potential temperature perturbation.

For most density currents in Table 1 , the percentage difference in the estimate of the maximum vertical velocity is 


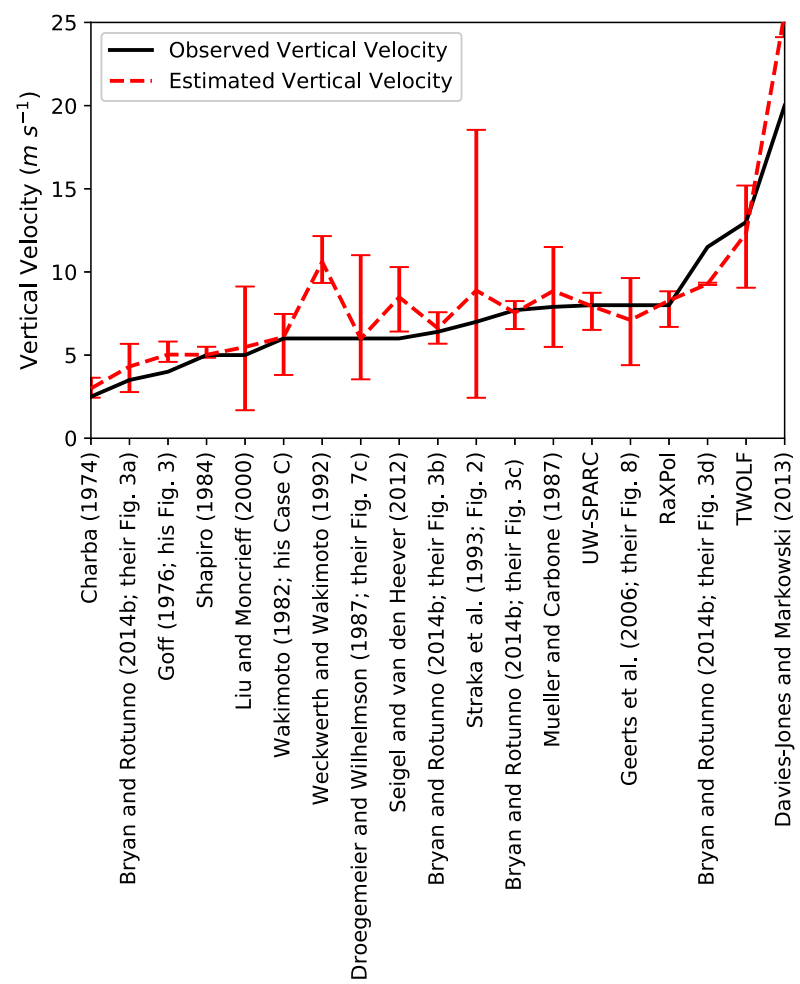

FIG. 17. Observed vertical velocity (solid line, $\mathrm{m} \mathrm{s}^{-1}$ ) and estimated vertical velocity using (7) (dashed line, $\mathrm{m} \mathrm{s}^{-1}$ ) for density currents from select past studies and the three on 15 Jul 2015 (denoted as UWSPARC, RaXPol, and TWOLF). This figure uses the information presented in Table 1 . The upper and lower limits on the error bars represent the value obtained from the maximum and minimum slope estimates, respectively, shown in Table 1.

$\pm 15 \%$ (Fig. 17). These differences are approximate since there were estimates made in some of the variables (especially in the estimate of the slope angle) and some of the "observed" velocities were estimated as well. These estimates were the result of the previous studies not having the variables stated explicitly, so we used their figures to estimate what they might have been.

For some studies (Weckwerth and Wakimoto 1992; Seigel and van den Heever 2012; Bryan and Rotunno 2014b), this methodology resulted in large $(>25 \%)$ percentage differences between the estimated and the observed vertical velocity. These differences are largely due to uncertainties in either the estimates slope of the density current or the potential temperature perturbation. If the potential temperature estimate was too large, then there was an overestimate in the maximum vertical velocity (e.g., the overestimate for the Straka et al. 1993 density current). A possible reason for the overestimate for the Weckwerth and Wakimoto (1992) density current is actually an underestimate in the observed vertical velocity owing to the dual-Doppler analysis smoothing out the vertical velocity field. However, despite these three large errors, the remaining estimates of vertical velocity are typically within $\pm 15 \%$.

\section{Summary}

This study introduced a method to estimate the maximum vertical velocity at the leading edge of a density current (assuming a steady-state, inviscid flow) using the following properties of the density current: its height, slope, and $\theta^{\prime}$. The applicability of this method was tested using idealized numerical simulations of density currents in different environmental stratifications. The estimates in the vertical velocity corresponded well with those of the simulated density currents, even as the environmental stratification increased. Additional tests in environments with vertical wind shear were performed and the method appears to account indirectly for this shear in the slope term. This indirect inclusion of features including environmental stratification and vertical wind shear makes this method applicable to density currents in a wide range of environments.

This method was also tested on three density currents observed during PECAN and several density currents documented in previous studies. For these previously studied density currents, there was a $\pm 15 \%$ difference between the estimated vertical velocity and the observed vertical velocity. There were outliers, but these outliers were likely the result of uncertainties in the estimate of variables such as the potential temperature perturbation or the slope of the density current head. Despite these outliers, this method provides a reasonable estimate of the vertical velocity at the leading edge of a density current.

Acknowledgments. We are extremely grateful to Dr. Rich Rotunno (NCAR) for useful conversations during the early phase of this research, to Dr. George Bryan (NCAR) for his assistance in utilizing CM1, and to Dr. Alan Shapiro (OU) for all of his useful discussions throughout this project. We are also grateful to Chris O'Handley (Simpson Weather Associates) for processing the TWOLF data. Some of the computing for this project was performed at the OU Supercomputing Center for Education and Research (OSCER) at OU. We also thank the Advanced Radar Research Center (ARRC) for maintaining RaXPol. Finally, we thank all of the people who made PECAN a possibility and those who participated in the field project. This project was supported by NSF Grants AGS-1262048 and AGS-1560945. The National Center for Atmospheric Research is sponsored by the National Science Foundation. The NCAR Advanced Study Program (ASP) supported the first author during a portion of this study.

Data availability statement. The PECAN data used in this study are available at https://data.eol.ucar.edu/master_lists/ generated/pecan/. For more information and/or access to the numerical simulations, please email the first author at dylanreif@ou.edu.

\section{REFERENCES}

Benjamin, T. B., 1968: Gravity currents and related phenomena. J. Fluid Mech., 31, 209-248, https://doi.org/10.1017/S0022112068000133.

Bluestein, H. B., and D. B. Parsons, 2016: RaXPol Radar Data, cfRadial format, version 1.0. UCAR/NCAR-Earth Observing Laboratory, accessed 29 August 2018, https://doi.org/10.5065/ D6VD6WV2. 
— J. B. Houser, M. M. French, J. C. Snyder, G. D. Emmitt, I. PopStefanija, C. Baldi, and R. T. Bluth, 2014: Observations of the boundary layer near tornadoes and in supercells using a mobile, collocated, pulsed Doppler lidar and radar. J. Atmos. Oceanic Technol., 31, 302-325, https://doi.org/ 10.1175/JTECH-D-13-00112.1.

Bryan, G. H., and R. Rotunno, 2014a: The optimal state for gravity currents in shear. J. Atmos. Sci., 71, 448-468, https://doi.org/ 10.1175/JAS-D-13-0156.1.

$\longrightarrow$, and — 2014b: Gravity currents in confined channels with environmental shear. J. Atmos. Sci., 71, 1121-1142, https:// doi.org/10.1175/JAS-D-13-0157.1.

_ J. C. Wyngaard, and J. M. Fritsch, 2003: Resolution requirements for the simulation of deep moist convection. Mon. Wea. Rev., 131, 2394-2416, https://doi.org/10.1175/1520-0493(2003) $131<2394:$ RRFTSO $>2.0$. CO;2.

Charba, J., 1974: Application of gravity current model to analysis of squall-line gust front. Mon. Wea. Rev., 102, 140-156, https://doi.org/10.1175/1520-0493(1974)102<0140:AOGCMT> 2.0.CO;2.

Chen, C., 1995: Numerical simulations of gravity currents in uniform shear flows. Mon. Wea. Rev., 123, 3240-3253, https://oi.org/ 10.1175/1520-0493(1995)123<3240:NSOGCI > 2.0.CO;2.

Clark, R., 2016: FP3 Ellis, KS radiosonde data, version 2.0. UCAR/ NCAR-Earth Observing Laboratory, accessed 29 August 2018, https://doi.org/10.5065/D6GM85DZ.

Crook, N. A., and M. W. Moncrieff, 1988: The effect of large-scale convergence on the generation and maintenance of deep moist convection. J. Atmos. Sci., 45, 3606-3624, https://doi.org/ 10.1175/1520-0469(1988)045<3606:TEOLSC >2.0.CO;2.

Davies-Jones, R., and P. Markowski, 2013: Lifting of ambient air by density currents in sheared environments. J. Atmos. Sci., 70, 1204-1215, https://doi.org/10.1175/JAS-D-12-0149.1.

Droegemeier, K. K., and R. B. Wilhelmson, 1985: Three-dimensional numerical modeling of convection produced by interacting thunderstorm outflows. Part I: Control simulation and low-level moisture variations. J. Atmos. Sci., 42, 2381-2403, https://doi.org/ 10.1175/1520-0469(1985)042<2381:TDNMOC >2.0.CO;2.

_ and - 1987: Numerical simulation of thunderstorm outflow dynamics. Part I: Outflow sensitivity experiments and turbulence dynamics. J. Atmos. Sci., 44, 1180-1210, https://doi.org/ 10.1175/1520-0469(1987)044<1180:NSOTOD>2.0.CO;2.

Geerts, B., R. Damiani, and S. Haimov, 2006: Finescale vertical structure of a cold front as revealed by an airborne Doppler radar. Mon. Wea. Rev., 134, 251-271, https://doi.org/10.1175/ MWR3056.1.

—_, and Coauthors, 2017: The 2015 Plains Elevated Convection At Night (PECAN) field project. Bull. Amer. Meteor. Soc., 98, 767-786, https://doi.org/10.1175/BAMS-D-15-00257.1.

Goff, R. C., 1976: Vertical structure of thunderstorm outflows. Mon. Wea. Rev., 104, 1429-1440, https://doi.org/10.1175/15200493(1976)104<1429:VSOTO>2.0.CO;2.

Grant, L. D., and S. C. ven den Heever, 2016: Cold pool dissipation. J. Geophys. Res. Atmos., 121, 1138-1155, https://doi.org/ 10.1002/2015JD023813.

Grasmick, C., B. Geerts, D. D. Turner, Z. Wang, and T. M. Weckwerth, 2018: The relation between nocturnal MCS evolution and its outflow boundaries in the stable boundary layer: An observational study of the 15 July 2015 MCS in PECAN. Mon. Wea. Rev., 146, 3203-3226, https://doi.org/ 10.1175/MWR-D-18-0169.1.

Haertel, P. T., R. H. Johnson, and S. N. Tulich, 2001: Some simple simulations of thunderstorm outflows. J. Atmos.
Sci., 58, 504-516, https://doi.org/10.1175/1520-0469(2001) $058<0504:$ SSSOTO $>2.0 . \mathrm{CO} ; 2$.

Haghi, K. R., D. B. Parsons, and A. Shapiro, 2017: Bores observed during IHOP_2002: The relationship of bores to the nocturnal environment. Mon. Wea. Rev., 145, 3929-3946, https://doi.org/ 10.1175/MWR-D-16-0415.1.

Hubbert, J. C., J. W. Wilson, T. M. Weckwerth, S. M. Ellis, M. Dixon, and E. Loew, 2018: S-Pol's polarimetric data reveal detailed storm features (and insect behavior). Bull. Amer. Meteor. Soc., 99, 2045-2060, https://doi.org/10.1175/BAMS-D-17-0317.1.

Hutson, A., C. Wiess, and G. Bryan, 2019: Using the translation speed and vertical structure of gust fronts to infer buoyancy deficits within thunderstorm outflow. Mon. Wea. Rev., 147, 3575-3594, https://doi.org/10.1175/MWR-D-18-0439.1.

Lane, T. P., and M. W. Moncrieff, 2015: Long-lived mesoscale systems in a low-convective inhibition environment. Part I: Upshear propagation. J. Atmos. Sci., 72, 4297-4318, https:// doi.org/10.1175/JAS-D-15-0073.1.

Liu, C., and M. W. Moncrieff, 2000: Simulated density currents in idealized stratified environments. Mon. Wea. Rev., 128, 1420-1437, https://doi.org/10.1175/1520-0493(2000)128<1420: SDCIIS > 2.0.CO;2.

Mahoney, W. P., 1988: Gust front characteristics and the kinematics associated with interacting thunderstorm outflows. Mon. Wea. Rev., 116, 1474-1492, https://doi.org/10.1175/15200493(1988)116<1474:GFCATK>2.0.CO;2.

Martner, B. E., 1997: Vertical velocities in a thunderstorm gust front and outflow. J. Appl. Meteor., 36, 615-622, https://doi.org/ 10.1175/1520-0450(1997)036<0615:VVIATG > 2.0.CO;2.

Mitchell, K. E., and J. B. Hovermale, 1977: A numerical investigation of the severe thunderstorm gust front. Mon. Wea. Rev., 105, 657-675, https://doi.org/10.1175/1520-0493(1977) 105<0657:ANIOTS>2.0.CO;2.

Moncrieff, M. W., and C. Liu, 1999: Convection initiation by density currents: Role of convergence, shear, and dynamical organization. Mon. Wea. Rev., 127, 2455-2464, https://doi.org/ 10.1175/1520-0493(1999)127<2455:CIBDCR>2.0.CO;2.

Mueller, C. K., and R. E. Carbone, 1987: Dynamics of a thunderstorm outflow. J. Atmos. Sci., 44, 1879-1898, https://doi.org/ 10.1175/1520-0469(1987)044<1879:DOATO>2.0.CO;2.

Pazmany, A. L., J. B. Mean, H. B. Bluestein, J. C. Snyder, and J. B. Houser, 2013: A mobile rapid-scanning X-band polarimetris (RaXPol) Doppler radar system. J. Atmos. Oceanic Technol., 30, 1398-1413, https://doi.org/10.1175/JTECH-D12-00166.1.

Reif, D. W., and Coauthors, 2016: T-WOLF (Truck-Mounted Wind Observing Lidar Facility) data, version 1.0. UCAR/ NCAR-Earth Observing Laboratory, accessed 29 August 2018, https://doi.org/10.5065/D6HQ3X8Q.

Rotunno, R., J. B. Klemp, and M. L. Weisman, 1988: A theory for strong, long-lived squall lines. J. Atmos. Sci., 45, 463-485, https:// doi.org/10.1175/1520-0469(1988)045<0463:ATFSLL>2.0.CO;2.

Seitter, K. L., 1986: A numerical study of atmospheric density current motion including the effects of condensation. J. Atmos. Sci., 43, 3068-3076, https://doi.org/10.1175/1520-0469(1986) $043<3068$ :ANSOAD $>2.0$.CO;2.

Shapiro, A., 1992: A hydrodynamical model of shear flow over semi-infinite barriers with application to density currents. J. Atmos. Sci., 49, 2293-2305, https://doi.org/10.1175/15200469(1992)049<2293:AHMOSF > 2.0.CO;2.

Shapiro, M. A., 1984: Meteorological tower measurements of a surface cold front. Mon. Wea. Rev., 112, 1634-1639, https://doi.org/ 10.1175/1520-0493(1984)112<1634:MTMOAS>2.0.CO;2. 
Seigel, R. B., and S. C. van den Heever, 2012: Simulated density currents beneath embedded stratified layers. J. Atmos. Sci., 69 , 2192-2200, https://doi.org/10.1175/JAS-D-11-0255.1.

Smith, R. K., and M. J. Reeder, 1988: On the movement and low-level structure of cold fronts. Mon. Wea. Rev., 116, 1927-1944, https://doi.org/10.1175/1520-0493(1988)116<1927: OTMALL $>2.0 . \mathrm{CO} ; 2$.

Soler, M. R., M. Udina, and E. Ferreres, 2014: Observational and numerical simulation study of a sequence of eight atmospheric density currents in northern Spain. Bound.-Layer Meteor., 153, 195-216, https://doi.org/10.1007/s10546-014-9942-2.

Straka, J. M., R. B. Wilhelmson, J. L. Wicker, J. R. Anderson, and K. K. Droegemeier, 1993: Numerical solutions of a non-linear density current: A benchmark solution and comparisons. Int. J. Numer. Methods Fluids, 17, 1-22, https://doi.org/10.1002/fld.1650170103.

UCAR/NCAR-Earth Observing Laboratory, 2016a: FP3 FP4 FP5 QC 5 min surface data, tile corrected, version 1.0. UCAR/ NCAR-Earth Observing Laboratory, accessed 29 August 2018, https://doi.org/10.5065/D6BZ645V.

- 2016b: S-Pol radar moments data in cfRadial format, version 2.0. UCAR/NCAR-Earth Observing Laboratory, accessed 29 August 2018, https://doi.org/10.5065/D6PN93VJ.

Wagner, T. J., D. Turner, and R. Newsom, 2016a: MP3 University of Wisconsin SPARC Doppler lidar zenith pointing data, version 2.0. UCAR/NCAR-Earth Observing Laboratory, accessed 29 August 2018, https://doi.org/10.5065/D6QJ7FJ5.

_ E. Olson, N. Smith, and W. Feltz, 2016b: Mobile PISA 3 UW/ SSEC SPARC radiosonde data, version 2.0. UCAR/NCAREarth Observing Laboratory, accessed 29 August 2018, https:// doi.org/10.5065/D6VH5M7B.

—, P. M. Klein, and D. D. Turner, 2019: A new generation of ground-based mobile platforms for active and passive profiling of the boundary layer. Bull. Amer. Meteor. Soc., 100, 137-153, https://doi.org/10.1175/BAMS-D-17-0165.1.

Wakimoto, R. M., 1982: The life cycle of thunderstorm gust fronts as viewed with Doppler radar and rawinsonde data. Mon. Wea. Rev., 110, 1060-1082, https://doi.org/10.1175/1520-0493(1982) 110<1060:TLCOTG $>2.0$. CO;2.

Weckwerth, T. M., and R. M. Wakimoto, 1992: The initiation and organization of convective cells atop a cold-air outflow boundary. Mon. Wea. Rev., 120, 2169-2187, https://doi.org/ 10.1175/1520-0493(1992)120<2169:TIAOOC>2.0.CO;2.

Weisman, M. L., and R. Rotunno, 2004: "A theory for strong long-lived squall lines" revisited. J. Atmos. Sci., 61, 361-382, https://doi.org/10.1175/1520-0469(2004)061<0361:ATFSLS> 2.0.CO;2.

White, B. L., and K. R. Helfrich, 2008: Gravity currents and internal waves in a stratified fluid. J. Fluid Mech., 616, 327-356, https://doi.org/10.1017/S0022112008003984.

Wilson, J. W., and W. E. Schreiber, 1986: Initiation of convective storms at radar-observed boundary-layer convergence lines. Mon. Wea. Rev., 114, 2516-2536, https://doi.org/10.1175/15200493(1986)114<2516:IOCSAR>2.0.CO;2.

_ , and D. L. Megenhardt, 1997: Thunderstorm initiation, organization, and lifetime associated with Florida boundary layer convergence lines. Mon. Wea. Rev., 125, 1507-1525, https://doi.org/ 10.1175/1520-0493(1997)125<1507:TIOALA>2.0.CO;2.

$\mathrm{Xu}$, Q., 1992: Density currents in shear flows-A two-fluid model. J. Atmos. Sci., 49, 511-524, https://doi.org/10.1175/ 1520-0469(1992)049<0511:DCISFA > 2.0.CO;2.

Ziegler, C. L., M. Coniglio, M. Parker, and R. S. Schumacher, 2016: CSU/NCSU/NSSL MGAUS radiosonde data, version 3.0. UCAR/NCAR-Earth Observing Laboratory, accessed 29 August 2018, https://doi.org/10.5065/D6W66HXN. 